NBER WORKING PAPER SERIES

\title{
PANEL DATA HEDONICS: \\ ROSEN'S FIRST STAGE AS A "SUFFICIENT STATISTIC"
}

\author{
H. Spencer Banzhaf \\ Working Paper 21485 \\ http://www.nber.org/papers/w21485 \\ NATIONAL BUREAU OF ECONOMIC RESEARCH \\ 1050 Massachusetts Avenue \\ Cambridge, MA 02138 \\ August 2015, Revised August 2019
}

I thank David Albouy, Olivier Beaumais, Kelly Bishop, Jared Carbone, Kerry Smith, Chris Timmins, Reed Walker and Jeffrey Zabel for helpful comments and suggestions on previous drafts. I am especially grateful to Paul Ferraro and Nick Kuminoff for very detailed comments and discussions. I also thank numerous seminar and conference participants. Finally, I thank Kelly Bishop and Chris Timmins for sharing the data used in Section 8. The views expressed herein are those of the author and do not necessarily reflect the views of the National Bureau of Economic Research.

NBER working papers are circulated for discussion and comment purposes. They have not been peerreviewed or been subject to the review by the NBER Board of Directors that accompanies official NBER publications.

(C) 2015 by H. Spencer Banzhaf. All rights reserved. Short sections of text, not to exceed two paragraphs, may be quoted without explicit permission provided that full credit, including $\bigcirc$ notice, is given to the source. 
Panel Data Hedonics: Rosen's First Stage as a "Sufficient Statistic"

H. Spencer Banzhaf

NBER Working Paper No. 21485

August 2015, Revised August 2019

JEL No. D46,D61,H4,Q51,R3

\begin{abstract}
Traditional cross-sectional estimates of hedonic price functions can recover marginal willingness to pay for characteristics, but face endogeneity problems for estimating non-marginal welfare measures. I show that when panel data on household demands are available, one can construct a second-order approximation to non-marginal welfare measures using only the first-stage marginal prices. With repeated cross sections of product prices, the measure can be set identified or, under a single-crossing restriction, point identified. Bounds also can be constructed when there are mobility costs. Finally, a variant remains valid when individual preferences shift over time.
\end{abstract}

H. Spencer Banzhaf

Department of Economics

Andrew Young School of Policy Studies

Georgia State University

P.O. Box 3992

Atlanta, GA 30302

and NBER

hsbanzhaf@gsu.edu

This paper is a revision of several sections of an earlier paper, "Panel Data Hedonics: Rosen's First Stage and Difference-in-Differences as Sufficient Statistics, " which was circulated in August 2015 as Working Paper 21485. A companion paper to this revision, which contains material in the original paper that is not included in this revision, may be found here. 


\title{
Panel Data Hedonics: Rosen's First Stage as a "Sufficient Statistic"
}

\begin{abstract}
Traditional cross-sectional estimates of hedonic price functions can recover marginal willingness to pay for characteristics, but face endogeneity problems for estimating non-marginal welfare measures. I show that when panel data on household demands are available, one can construct a second-order approximation to non-marginal welfare measures using only the first-stage marginal prices. With repeated cross sections of product prices, the measure can be set identified or, under a single-crossing restriction, point identified. Bounds also can be constructed when there are mobility costs. Finally, a variant remains valid when individual preferences shift over time.
\end{abstract}

\section{Introduction}

For decades, the hedonic model has been the starting point for understanding people's values for differentiated products (see Palmquist 2005 for a review). Its applications include willingness to pay (WTP) in higher housing prices for local public goods and spatial amenities, compensating wage differentials for attributes such as job safety, pricing of quality-differentiated consumer products such as computers and cars, and quality-adjustments in national accounting.

Part of the hedonic model's appeal has always been the simple relationship between hedonic prices and consumer demand: the derivative of a hedonic price function with respect to a characteristic is equal to a household's marginal WTP for the characteristic. This aspect of the model is highly appealing because price functions can feasibly be estimated with simple, transparent research designs, yet they also have a clear welfare interpretation. However, the marginal WTP potentially observed from only the hedonic price gradient is generally viewed as inadequate information for welfare evaluations of large policy shocks. Accordingly, since Rosen (1974), economists have sought to identify households' willingness-to-pay functions for amenities in a second stage. But recovering these willingness-to-pay functions from a single cross section has proved to be a challenge. Because only one point on each individual's demand function is observed (where marginal WTP is equal to the derivative of the hedonic price function), the only variation in the data comes from the way different households sort across choice alternatives in equilibrium. The standard solution is to model heterogeneity in individual demands. Unfortunately, the unobserved components in demand (e.g. tastes) systematically vary both with levels of amenities and their marginal prices. This correlation gives rise to a well-known endogeneity problem (Bartik 1987, 
Epple 1987, Heckman, Matzkin, and Nesheim 2010a, Bishop and Timmins 2019).

Proposed solutions to this problem combine, in one way or another, the economic logic of sorting along with some structure imposed on heterogeneity in tastes. In the hedonic model, Ekeland, Heckman, and Nesheim (2004) note that nonlinearities in the equilibrium price function justify using nonlinear functions of observed demand shifters as instruments for the observed quantities demanded. Heckman, Matzkin, and Nesheim (2005, 2010a) and Bishop and Timmins (2019) discuss strategies for imposing functional form restrictions that allow one to map quantities of characteristics into demands. Departing somewhat from the continuous world of the hedonic model, structural models of discrete choices follow a similar basic strategy (see Kuminoff, Smith, and Timmins 2013 for a review). In general, because the economics of the models imply a particular mapping from households' preferences to the way they sort in equilibrium, the logic can be inverted to recover preferences from observed sorting, conditional on the assumed structure. Typically, this involves imposing distributional assumptions about unobserved tastes. For example, they may be assumed to have an extreme value distribution (e.g. Bayer, Ferreira, and McMillan 2007) or a log-normal distribution (e.g. Sieg et al. 2004); similarly, WTP functions may be assumed to have errors following some known distribution (e.g. normal in Bishop and Timmins 2019). Alternatively, one can relax these distributional assumptions but forego point identification of the underlying parameters (Kuminoff 2012). This literature has provided a tremendous advance on our ability to model general equilibrium counterfactuals as well as non-marginal welfare effects. However, these advantages come at the price of imposing additional structure and complication - thus losing some of the simple reduced-form appeal of the hedonic model.

As Bajari and Benkard (2005), Kuminoff and Pope (2012), and Bishop and Timmins (2018) have pointed out, the problem becomes considerably easier when individuals are observed in multiple settings, as then individuals' willingness-to-pay functions can be fitted to two or more points. To my knowledge, however, the literature has not noticed that when households are observed two or more times, their observed choices, together with knowledge of the first stage hedonic price functions, are sufficient to estimate welfare measures that are proportional to secondorder approximations to a change in utility for any constant utility function-without explicitly modeling heterogeneity at all and without imposing any distributional assumptions on unobserved 
demand parameters. ${ }^{1}$ With the advent of "big data," such panels are becoming increasingly available, even in the context of housing markets. For example, in the United States, researchers have made use of data available under the Home Mortgage Disclosure Act (HMDA) to match households to the houses they live in over time (e.g. Palmquist 1984 and, more recently, Bayer et al. 2012, and Bishop and Timmins 2018). In principle, such data may be even easier to come by in other contexts, such as automobile or computer purchases.

In this paper, I show how such data provide an opportunity to reinterpret the hedonic model in the spirit of calls from Chetty (2009) and Heckman (2010) to seek compromises that combine the clarity of reduced form econometric models with the ability of structural models to speak to welfare effects. With multiple time periods, it is possible to combine the logic of the hedonic model with estimation of only the first stage hedonic price function to identify non-marginal welfare effects under minimal assumptions about demand functions. This is in contrast to the standard view that knowledge of the hedonic price function alone is insufficient to analyze welfare effects of large policy shocks with general equilibrium effects. The logic parallels Harberger's (1971) argument for thinking of consumer surplus in terms of an index number, averaging ex ante and ex post marginal values. Information from only the first stage can produce a "sufficient statistic" for welfare measurement.

In particular, I consider monetary measures, constructed from the first-stage hedonic model, of the change in welfare associated with a change from one hedonic equilibrium to another, where exogenous amenities, price functions, and even incomes potentially differ. This change is of interest in at least two contexts. First, we may be interested in comparisons of welfare between two scenarios, as in cost-of-living indices or comparisons of real income. Banzhaf (2005), Timmins (2006), and Quintero, Epple, and Sieg (2019), among others, consider hedonic approaches to such questions. ${ }^{2}$ Second, we may be interested in the general equilibrium effect of specific policy

\footnotetext{
${ }^{1}$ Kuminoff and Pope (2012) suggest using exogenous shifts in the supply of amenities to derive withinmarket instruments for Rosen's "second stage." Although their suggestion is based on the same basic insight of this paper (that exogenous supply shocks can trace out a demand curve), in contrast I am suggesting that a similar procedure replace the second stage entirely, to identify a sufficient statistic for welfare measurement without estimating the deep structural parameters.

${ }^{2}$ This application is different from the goal of identifying partial equilibrium welfare measures of (potentially) out-of-sample policies. In this sense, this paper follows somewhat in the tradition of the capitalization literature (Lind 1973, Starrett 1981, Kuminoff and Pope 2014, Banzhaf 2018), in which one looks to changes in the hedonic equilibrium to evaluate in-sample shocks.
} 
or information shocks that represent a sudden change in conditions, such as discovery of a cancer cluster (Davis 2004) or the release of school report cards (Figlio and Lucas 2004). If these involve exogenous shocks to $g$ or income, we can find the welfare effect of the shocks, even when there are endogenous changes to hedonic prices and other amenities. This second context is a special case of the first: if there is one exogenous shock, then the change in conditions can be attributed to it.

I first show that when one can track households over time, one can construct a secondorder approximation to a Hicksian welfare measure by taking the change in the amenities experienced by the household multiplied by an average of the derivatives of the hedonic price function over time. The basic model assumes no transactions costs and constant demand functionals (of hedonic price functions) over time.

I next show that even if one cannot track households over time, one can bound the approximation by "searching" over all possible ways that households sort, using a simple linear program that respectively minimizes or maximizes the welfare measure. Alternatively, one can impose additional structure (in particular, a single crossing property) to impute how households sort. As I discuss in the paper, even if this property is not taken as literally true, as long as sorting patterns are correlated over time, errors from the assumption largely cancel out, so it makes for a reasonable approximation.

Finally, I relax the assumptions of no transactions costs and constant demands. In the case of no transactions costs, I again derive bounds on the welfare measure of interest in the case where households are myopic. If they are forward-looking, the recent results of Bishop and Murphy (2019) apply. In the case of constant demands, I show how the approach of the paper can be reinterpreted as evaluating welfare from a single time period's perspective, a paradigm suggested by Fisher and Shell (1972) and Pollak (1989).

Additionally, I demonstrate these results using both simulations of hedonic equilibria and an empirical application. The results of the simulations are consistent with the predicted relationships to true values. The sufficient statistic approach is a compromise between two Hicksian welfare measures, compensating variation (CV) and equivalent variation (EV). I also find that, when we relax some of the required assumptions, the bounds on welfare hold. The empirical application illustrates how hedonic data, such as those in a recent application to reductions in violent crime 
(Bishop and Timmins 2019), can easily be used to compute welfare estimates. The results are similar to estimates from the more structural model of Rosen (1974).

To fix ideas, I specifically discuss the example of housing markets with spatially varying amenities and I primarily discuss connections to that literature. However, the implications of this paper are not limited to that setting and apply equally to labor markets or to other contexts with differentiated commodities.

\section{Model Basics}

Consider a closed city (or region) with a constant set of households. ${ }^{3}$ Let $\mathcal{H}$ denote the set of houses with typical element $h$ and let $\mathcal{J}$ denote the set of households with typical element $i$. Equilibrium at each point in time consists of a bijective mapping of households to houses (all households occupy a house and all houses are occupied by a household). For expositional purposes, residents and landlords can be thought of as two separate groups, but there is nothing requiring this assumption.

Houses are differentiated by price $p$, an exogenous amenity $g$, and a vector of continuous housing characteristics $\mathbf{x}$ with characteristics indexed by $r=\{1, \ldots, R\}$ (lot size, dwelling size, and so forth). (The variable $g$ may be thought of as an index of public goods, or alternatively other public goods of secondary interest may be thought to be embedded in $\mathbf{x}$.) Notationally, it will sometimes be more convenient to work with a more parsimonious notation with the vector $\mathbf{z}^{\prime}=[g$, $\mathbf{x}^{\prime}$ ] and with the elements of $\mathbf{z}$ indexed by $j$.

At any point in time $t$, households differ by their income $y$ and by their current-period preferences, which can be represented by a twice differentiable quasi-concave conditional indirect utility function $v_{i}^{t}\left(y_{i}^{t}-p_{h}, g_{h}, \mathbf{x}_{h}\right)$, with $\partial v_{i}^{t} / \partial y_{i}^{t}>0$ and $\partial v_{i}^{t} / \partial \mathrm{g} \neq 0$ everywhere $\forall i$. Note that $-\partial v_{i}^{t} / \partial p=\partial v_{i}^{t} / \partial y_{i}^{t} \equiv \lambda_{i}^{t}$, the marginal utility of money.

On the supply side of the market, the profit function for house $h$ is $\pi_{h}=p_{h}-c_{h}\left(\mathbf{x}_{h}\right)$, where the cost function $c_{h}$ ( ) is twice differentiable. For convenience, $c_{h}($ ) is constant over time, although this assumption could be relaxed.

\footnotetext{
${ }^{3}$ The area modeled does not literally need to be one city (or housing market). Nor need it coincide with the area affected by the policy of interest. However, as always, economists modeling demand must make judgments about the set of relevant substitutes.
} 
Consider two moments in time, with $t=0$ in the initial situation and $t=1$ in a later situation. Let $F^{t}($ ) be the distribution function of $g$ at time $t$. Prices of houses are determined by the amenities and the equilibrium price function: $p_{h}^{t}=p^{t}\left(\mathrm{~g}_{h}^{t}, \mathbf{x}_{h}^{t}\right)$. The time superscript on the hedonic price function indicates that equilibrium hedonic prices may shift over time, because of changes in $g$, in income, or other aspects of the economic environment. In the initial situation, the household maximizes utility over a continuous choice set defined by the continuously differentiable hedonic function $p^{0}=p^{0}\left(g^{0}, \mathbf{x}^{0}\right)$. There is then an exogenous shock to the distribution of $g$ available in the city, and/or to incomes. Consequently, the equilibrium price function adjusts to $p^{1}=p^{1}\left(g^{1}, \mathbf{x}^{1}\right)$, with the set of other available characteristics $\mathbf{x}$ possibly changing endogenously. It is this change in the hedonic environment that will be evaluated.

Initially, I make the standard hedonic assumption that households are in a static equilibrium at both points in time, either because they choose a new product regularly (as would be fitting for applications to consumer products) or because they can costlessly re-optimize. ${ }^{4}$ Maximizing utility at time $t$, the household satisfies the first-order condition:

$$
\frac{\partial p^{t}}{\partial z_{j}}=-\frac{\partial v_{i}^{t} / \partial z_{j}}{\partial v_{i}^{t} / \partial p}=\frac{\partial v_{i}^{t} / \partial z_{j}}{\lambda_{i}^{t}}
$$

Equation (1) represents the standard tangency condition, in which the derivative of the hedonic function with respect to an amenity is equal to marginal WTP for the amenity at the optimal point.

Similarly, the landlord's first-order condition for profit maximization is

$$
\frac{\partial c_{h}}{\partial x_{r}}=\frac{\partial p^{t}}{\partial x_{r}}
$$

That is, the endogenous amenities $\mathbf{x}$ are supplied according to similar tangency condition, with marginal cost of supply equal to the marginal revenue.

\footnotetext{
${ }^{4}$ This assumption continues to underlie the vast majority of work on hedonic markets (e.g. Ekeland, Heckman, and Nesheim 2004, Bajari and Benkard 2005, Heckman, Matzkin, and Nesheim 2010, Bishop and Timmins 2018) as well as structural sorting models of locational choice (e.g. Sieg et al. 2004 Bayer, Ferreira, and McMillan 2007, Kuminoff 2012). However, recent work is beginning to consider dynamic optimization in the context of transaction costs, which may be substantial in applications to housing (Kennan and Walker 2011, Bishop 2012, Bayer et al. 2016, Bishop and Murphy 2019). The labor literature has a longer tradition of considering such dynamic optimization (e.g. Keane and Wolpin 1997).
} 
The basic problem is to make inferences about non-marginal welfare effects from these primitive conditions.

\section{Non-Marginal Values when Demands are Constant and a Panel of Households Is Availa- ble: The Hedonic Harberger Triangle}

As a starting point, consider the arguably restrictive case covered by the following three assumptions.

Assumption A1 (Panel of Households). Panel data on household choices are available, so that $p$ and $\partial p^{t} / \partial z_{j}$ can be evaluated for each household at each point in time at their choice of $\mathbf{z}$.

Assumption A2 (No transactions Costs). There are no transactions costs, so the household always satisfies the first-order condition given by Equation (1).

Assumption A3 (Constant Preferences). Households' preferences are constant over the time period considered: $v_{i}^{t}\left(y_{i}^{t}-p_{h}, g_{h}, \mathbf{x}_{h}\right)=v_{i}\left(y_{i}^{t}-p_{h}, g_{h}, \mathbf{x}_{h}\right) \forall t$, so that the optimal vector $\mathbf{x}$ and $g$ are unchanging functionals of income and the hedonic price function.

In this subsection, I show that, under Assumptions A1-A3, a second-order approximation

of the general equilibrium welfare effects of a change in conditions can be constructed using only estimated marginal prices from the first stage hedonic price regression and aggregate changes in income. The assumptions essentially guarantee that observed shifts in the hedonic price function trace out the marginal value function (A2 and A3), and that points on the function are observed (A1). In subsequent sections, Assumptions A1-A3 will be relaxed in turn.

Following Harberger (1971), consider a second order approximation to a change in utility for an individual in the hedonic model given Assumption A2:

$$
\begin{aligned}
\Delta v_{i} \approx \frac{\partial v_{i}}{\partial y}\left(\Delta y_{i}-\Delta p_{i}\right)+\sum_{j} \frac{\partial v_{i}}{\partial z_{j}} \Delta z_{j, i}+\frac{1}{2} \frac{\partial^{2} v_{i}}{\partial y^{2}}\left(\Delta y_{i}-\Delta p_{i}\right)^{2} \\
+\sum_{j} \frac{\partial^{2} v_{i}}{\partial y \partial z_{j}}\left(\Delta y_{i}-\Delta p_{i}\right) \Delta z_{j, i}+\frac{1}{2} \sum_{j^{\prime}} \sum_{j} \frac{\partial^{2} v_{i}}{\partial z_{j} \partial z_{j^{\prime}}} \Delta z_{j, i} \Delta z_{j^{\prime}, i}
\end{aligned}
$$

where $\Delta p_{i}=p^{1}\left(\mathrm{~g}_{i}^{1}, \mathbf{x}_{i}^{1}\right)-p^{0}\left(\mathrm{~g}_{i}^{0}, \mathbf{x}_{i}^{0}\right)$ is the household's change in expenditure and $\Delta z_{j, i}$ is the change in amenity $j$ experienced by household $i$ after all adjustments. These changes stem from a number of sources. At the household's initial optimal location, $g$ may change exogenously (e.g. from a policy shock) and the price of the home may capitalize this change. Incomes also may 
change, exogenously or indirectly in equilibrium. Additionally, $p$ changes as the hedonic function shifts. Finally, $p, g$, and $\mathbf{x}$ may all change from any readjustments by the household as it re-optimizes, and $\mathbf{x}$ also may change from any supply-side investments as landlords re-optimize. Whatever the source of the changes, the welfare effects are evaluated taking all of them into account.

Harberger's strategy reduces the problem of measuring non-marginal willingness to pay to an index number, that is, to an average of marginal Marshallian WTP along the path between $\left[p^{0}, g^{0}, \mathbf{x}^{0}, y^{0}\right]$ and $\left[p^{1}, g^{1}, \mathbf{x}^{1}, y^{1}\right]$. Although it is based on a Marshallian construct, he showed that it also could be interpreted as a valid approximation to an exact welfare measure. ${ }^{5}$ More recently, Chetty (2009) has suggested that Harberger's approach can be thought of as setting a paradigm for sufficient-statistic welfare measurement.

Equation (3) leads to the following lemma.

LEMMA 1. Given Assumptions A1-A3, a second order approximation to the change in welfare for each consumer, $\Delta w_{i}$, from an exogenous change in the distribution of $g$, can be constructed from observed prices and estimated marginal prices as follows:

$$
\Delta w_{i} \equiv \frac{\Delta v_{i}}{\frac{1}{2}\left(\lambda_{i}^{0}+\lambda_{i}^{1}\right)} \approx \Delta y_{i}-\Delta p_{i}+\sum_{j} \frac{1}{2}\left(\left.\frac{\partial p^{0}}{\partial z_{j}}\right|_{\mathbf{z}_{i}^{0}}+\left.\frac{\partial p^{1}}{\partial z_{j}}\right|_{\mathbf{z}_{i}^{1}}\right) \Delta z_{j, i} .
$$

Proof: See the appendix.

This expression is proportional to the utility change $\Delta v$, which is converted to the measuring rod of money using the average marginal utility of income, averaged between the starting point and ending point. Lemma 1 states that this monetary value of the change in welfare for a consumer is given by the change in income, the change in rents $\Delta p$, plus the change in housing attributes and public goods experienced by the household after all adjustments, multiplied by the average marginal WTP, again averaged between the starting point and ending point. The expression might be thought of as a "hedonic Harberger triangle" (or trapezoid). It is a compromise between two Hicksian measures, $\mathrm{CV}$ and $\mathrm{EV}$.

On the supply side of the market, landlords are directly better off by the change in rents $\Delta p$. This change in rents stems from shifts in the price function and from exogenous changes in $g$,

\footnotetext{
${ }^{5}$ See Banzhaf (2010) for a discussion of this approach to welfare measurement in a historical context.
} 
but also potentially from adjustments to $\mathbf{x}$ that are costly to supply. Consequently, the cost of producing the change in $\mathbf{x}$ must be netted out of the change in profits. The change in profits from any change in $g$, the price function $p$ ( ), or endogenous adjustments to $\mathbf{x}$ is $\Delta \pi=\Delta p-\Delta c$. We can in turn take a second-order approximation to $\Delta c$ as follows.

$$
\Delta c_{h} \approx \sum_{r} \frac{\partial c_{h}}{\partial x_{r}} \Delta x_{r, h}+\frac{1}{2} \sum_{r^{\prime}} \sum_{r} \frac{\partial^{2} c_{h}}{\partial x_{r} \partial x_{r \prime}} \Delta x_{r, h} \Delta x_{r, h}
$$

This fact along with the first-order conditions leads to the following lemma.

LEMMA 2. A second order approximation to the change in profits for each landlord, $\Delta \pi_{h}$, can be constructed from observed prices and estimated marginal prices as follows:

$$
\Delta \pi_{h} \approx \Delta p_{h}-\sum_{r} \frac{1}{2}\left(\left.\frac{\partial p^{0}}{\partial x_{r}}\right|_{\mathbf{z}_{h}^{0}}+\left.\frac{\partial p^{1}}{\partial x_{r}}\right|_{\mathbf{z}_{h}^{1}}\right) \Delta x_{r, h}
$$

Proof: See the appendix.

LEMMA 2 says that the change in profits is just the change in price, net of an adjustment accounting for changes in costs due to endogenous changes in $\mathbf{x}$, which can be approximated from marginal prices.

Let the change in aggregate welfare $W$ be given by aggregating over the changes in consumer surplus and profits:

$$
\Delta W \equiv \int_{\mathcal{J}} \Delta w_{i} d i+\int_{\mathcal{H}} \Delta \pi_{h} d h
$$

By lemmas 1 and 2, we can integrate over Expressions (4) and (6) and substitute them into the respective terms in Equation (7). Additionally, we can combine these into one integral, but doing so requires some additional notation, because Expression (4) is evaluated at the choices made by a single household $i$ (regardless of location), whereas Expression (6) is evaluated at a particular house $h$ (regardless of who lives there). Let $\boldsymbol{z}_{i(\tau)}^{t}$ represent the characteristics, in time $t$, of a house actually occupied by household $i$ in time $\tau$. Similarly, let $\left.\frac{\partial p^{t}}{\partial z_{j}}\right|_{\mathbf{z}_{i(\tau)}^{t}}$ be the partial derivative of the time $t$ hedonic price function with respect to attribute $j$, evaluated at the time $t$ attributes of the house actually occupied by household $i$ in time $\tau$. By definition, $\boldsymbol{z}_{i(t)}^{t}=\boldsymbol{z}_{i}^{t}$. However, this more 
general notation allows us to keep track of a household's former house or future house, even when it is not currently living there.

Equation (7) together with this notation lead to the following proposition.

Proposition 1. Given Assumptions A1-A3, a second-order approximation to the change in aggregate welfare from a change in hedonic conditions, when prices, households, and landlords adjust to the change endogenously, is

$$
\begin{aligned}
d W \approx \int_{\mathcal{J}}[ & \Delta y_{i} \\
+ & \frac{1}{2}\left(\left.\frac{\partial p^{0}}{\partial \mathrm{g}}\right|_{\mathbf{z}_{i(0)}^{0}}+\left.\frac{\partial p^{1}}{\partial \mathrm{g}}\right|_{\mathbf{z}_{i(1)}^{1}}\right) \Delta \mathrm{g}_{i} \\
& +\sum_{r} \frac{1}{2}\left(\left.\frac{\partial p^{0}}{\partial x_{r}}\right|_{\mathbf{z}_{i(0)}^{0}}+\left.\frac{\partial p^{1}}{\partial x_{r}}\right|_{\mathbf{z}_{i(1)}^{1}}\right)\left(x_{r, i(1)}^{1}-x_{r, i(0)}^{1}\right) \\
& \left.+\sum_{r} \frac{1}{2}\left(\left.\frac{\partial p^{1}}{\partial x_{r}}\right|_{\mathbf{z}_{i(1)}^{1}}-\left.\frac{\partial p^{1}}{\partial x_{r}}\right|_{\mathbf{z}_{i(0)}^{1}}\right)\left(x_{r, i(0)}^{1}-x_{r, i(0)}^{0}\right)\right] d i .
\end{aligned}
$$

Proof: The proposition follows from Lemmas 1 and 2, simply integrating (4) over $\mathcal{J}$ and (6) over $\mathcal{H}$, adding the two together, fixing our indices so $h=i(0)$ (which we can do given the bijective mapping between them), and re-arranging terms. ${ }^{6}$

Expression (8) consists of four terms. The first is the change in income. The second is the change in $g$ experienced by a household (across houses if it moves) evaluated at the average of the partial derivatives of the hedonic price function at those two points. This term accounts for changes in exogenous amenities, which don't involve decisions by suppliers. The third and fourth terms together account for the effect of endogenous housing characteristics on both the demand and supply side. The third term is the change in $\mathbf{x}$ experienced by the household, accounting for the fact that it may change houses, but holding $\mathbf{x}$ fixed at any given house (i.e. netting out any supply adjustments), but with these changes again evaluated by the respective average partial derivatives experienced by the household (across houses). The fourth term is the supply response at the household's initial house, multiplied by the difference in the ex post partial derivatives between the final location and the initial location. The changes in prices $\Delta p$ which appear in Expressions (4)

\footnotetext{
${ }^{6}$ The first pair of terms in parentheses in Expression (8) comes from Expression (4). Adding the other terms of Expressions (4) and (6), we have $\frac{1}{2} \sum_{r}\left(\left.\frac{\partial p^{0}}{\partial x_{r}}\right|_{\mathbf{z}_{i(0)}^{0}}+\left.\frac{\partial p^{1}}{\partial x_{r}}\right|_{\mathbf{z}_{i(1)}^{1}}\right) d x_{r, i}-\frac{1}{2} \sum_{r}\left(\left.\frac{\partial p^{0}}{\partial x_{r}}\right|_{\mathbf{z}_{i(0)}^{0}}+\right.$ $\left.\left.\frac{\partial p^{1}}{\partial x_{r}}\right|_{\mathbf{z}_{i(0)}^{1}}\right) d x_{r, i(0)}$. We can write $d x_{r, i}=\left(x_{r, i(1)}^{1}-x_{r, i(0)}^{1}\right)+\left(x_{r, i(0)}^{1}-x_{r, i(0)}^{0}\right)=\left(x_{r, i(1)}^{1}-x_{r, i(0)}^{1}\right)+$ $d x_{r, i(0)}$. The rest follows by regrouping terms.
} 
and (6) cancel out as transfers between households and landlords.

Proposition 1 is the key result of this section. It says that, under our assumption that we observe a panel of housing attributes and our initial assumption that we can track households across locations, a second-order approximation to welfare can be estimated with only the derivatives of the first-stage hedonic price function at the two points in time, plus aggregate changes in income. The approach essentially relies on the fact that the policy shock induces a new equilibrium, which allows demands to be approximated by tracing out the optimized points.

Even if the city is not closed, Proposition 1 would apply to the sub-set of households we can track over time, as well as for the landlords in the area being tracked.

Expression (8) can be simplified if we are willing to assume that the supply side of the market is highly competitive and that profits (and rents to fixed factors) from adjustments to $\mathbf{x}$ are approximately zero. Denote this as Assumption A4:

Assumption A4 (No change in profits). The change in profits due to adjustments in $\mathbf{x}$ are approximately zero: $\int_{h}\left[p^{1}\left(\mathrm{~g}_{h}^{1}, \mathbf{x}_{h}^{1}\right)-p^{1}\left(\mathrm{~g}_{h}^{1}, \mathbf{x}_{h}^{0}\right)\right] d h \approx \int_{h}\left[c\left(\mathrm{~g}_{h}^{1}, \mathbf{x}_{h}^{1}\right)-c\left(\mathrm{~g}_{h}^{1}, \mathbf{x}_{h}^{0}\right)\right] d h$.

Thus, the change in profits consists only of the change in rents to land and to the inherited capital: $\int_{h} d \pi d h \approx \int_{h}\left(p^{1}\left(\mathrm{~g}^{1}, \mathbf{x}^{0}\right)-p^{0}\right) g_{i} d h=\int_{h}\left[\Delta p-\left(p^{1}-p^{1}\left(\mathrm{~g}^{1}, \mathbf{x}^{0}\right)\right)\right] d h$. That is, the landlord may receive higher (or lower rents) from the exogenous change in amenities, but the equilibrium adjustment to the endogenous characteristics $\mathbf{x}$ do not add to profits.

For simplicity, I will use Assumption A4 for the remainder of this paper. I will also assume that there are no aggregate changes of incomes: $\int_{\mathcal{J}} \Delta y_{i} d_{i}=0$. However, except for Section 4.2, these choices plays no substantive part of the results later derived, and parallels could be derived based on the more general results as well. In this case, we would have the following variant of Proposition 1:

Proposition 2. Given Assumptions A1-A4, and assuming no changes in aggregate income, a second-order approximation to the change in hedonic conditions, when prices, households, and landlords adjust to the change endogenously, is:

$$
d W \approx \int_{\mathcal{J}} \sum_{j} \frac{1}{2}\left(\left.\frac{\partial p^{0}}{\partial z_{j}}\right|_{\mathbf{z}_{i}^{0}}+\left.\frac{\partial p^{1}}{\partial z_{j}}\right|_{\mathbf{z}_{i}^{1}}\right) d z_{j, i} d i-\int_{\mathcal{H}}\left(p_{h}^{1}-p_{h}^{1}\left(\mathbf{x}^{0}, \mathbf{g}^{1}\right)\right) d h .
$$


Proof: The proposition follows immediately from applying Assumption A4 and $\int_{\mathcal{J}} \Delta y_{i} d_{i}=0$ to Proposition 1.

Proposition 2 states that we can measure benefits by tracking the change in amenities experienced by each household, weighted by the average of the derivatives of the two hedonic price functions evaluated at the households' choice, netting out any aggregate price changes that reflect real costs of adjustments in $\mathbf{x}$.

Note finally that in the simple case where there are no supply adjustments, then $x_{i(0), r}^{1}=$ $x_{i(0), r}^{0}$ and the entire expression collapses to

$$
d W \approx \int_{\mathcal{J}} \sum_{j} \frac{1}{2}\left(\left.\frac{\partial p^{0}}{\partial z_{j}}\right|_{\mathbf{z}_{i}^{0}}+\left.\frac{\partial p^{1}}{\partial z_{j}}\right|_{\mathbf{z}_{i}^{1}}\right) d z_{j, i} d i
$$

Expression (10) is just the individual household measure from Expression (4) summed over households, but with the $\Delta p$ terms cancelling as transfers between residents and landlords. It is similar to the partial equilibrium measure recently suggested by Bishop and Timmins (2018).

Figure 1 illustrates this measure, or equivalently this portion of the Expressions (8) and (9). The figure shows the derivatives with respect to $g$ of both the $t=0$ and $t=1$ hedonic functions; these derivatives are positive and continuous but unrestricted as to slope or curvature. The line bid $(g)$ represents the linearized approximation to the Marshallian marginal WTP function. ${ }^{7}$ The points $g^{0}$ and $g^{1}$ represent the levels of the public good selected by the consumer in each scenario. Although it is a Marshallian measure, the area under the linearized marginal WTP function represents a second-order approximation to the welfare change associated with the change in equilibria. The figure illustrates this measure only in the dimension of $g$, but note Expressions (8) to (10) require summing over all attributes $j$. Even if there are no adjustments to $\mathbf{x}$ in the housing stock as a result

\footnotetext{
${ }^{7}$ The interpretation of the Marshallian bid functions requires some nuance. As noted above, the marginal values for $g$ are along a path where non-linear prices and, potentially, incomes are changing. Thus, it is not like a Marshallian demand curve at constant income. Even if incomes are constant, in the hedonic context, as other non-linear pricing contexts (e.g. Wilson 1993), the Marshallian quantity demanded of a characteristic depends on the entire price function, not just the marginal price at the quantity demanded. Consider a consumer at some optimal point in characteristic space. If there is now a shift in the infra-marginal portions of the hedonic price function, in a way that leaves the marginal prices unchanged, the consumer may still re-optimize because of the income effect associated with the infra-marginal expenditure. These and any other income effects are incorporated into the welfare measure derived in this paper.
} 
of the policy, the welfare measure for this change in $g$ still requires taking these terms into account, weighted by the average marginal WTP of the household. The measures are no different if people are owner-occupiers. In that case, the wealth effects still cancel and the $d \mathbf{z}$ terms incorporate the wealth effects on demand for attributes, as would be appropriate. Regardless, a valid welfare measure can be obtained simply by adding up experienced changes in characteristics, weighted by the average marginal values.

\section{When Households Panels are not Available}

The previous subsection involves Assumption A1, that panel data on households' choices are available. Though increasingly available, they are not always. This subsection considers what we can learn if we relax this assumption.

First, to see the role of Assumption A1, note that Propositions 1 and 2 introduce expressions involving $\sum_{j} \frac{1}{2}\left(\left.\frac{\partial p^{0}}{\partial z_{j}}\right|_{\mathbf{z}_{i}^{0}}+\left.\frac{\partial p^{1}}{\partial z_{j}}\right|_{\mathbf{z}_{i}^{1}}\right) \Delta z_{j, i}$ for each household $i$. This expression involves observing (i) in which house each household lives at both points in time; (ii) a panel of house attributes $(g, \mathbf{x})$ or, if we are willing to assume $\Delta \mathbf{x}=0$, a panel of $g$ together with data on $\mathbf{x}$ at one time period; and (iii) either a panel of house prices (as in a repeat sales model) or repeated cross sections of housing prices sufficient for predicting $p_{h}$ at each location. Of these, the first is the most difficult to observe: in many cases analysts may observe housing characteristics and a sample of prices, but have no information whatsoever on who is occupying those houses. Unfortunately, in general such data are not sufficient to use the strategy outlined in the previous sub-section. Expression (9) requires information on the household's change in amenities, $\Delta \mathbf{z}_{i}$. In general, information on the change in amenities at a fixed house $h, \Delta \mathbf{z}_{h}$, is not sufficient. The problem is depicted in Figure 2. The figure shows two points respectively chosen by two households at the first point in time and two at the second. However, which household sorts into which house is unobserved. Consequently, the two households' demand curves may be the two solid lines or alternatively the two dashed lines. But the sums of the areas under those respective pairs of demand curves are not the same, differing by area (B-A) depicted in the figure.

Without the information on households' micro choices required for the results in Section 3, we can pursue two alternative strategies. The first is to acknowledge we can no longer pointidentify the second-order approximation, and to instead identify bounds on welfare. The second 
is to impose more structure. The following two sub-sections consider each strategy in turn.

\subsection{Non-parametric bounds on welfare}

As depicted in Figure 2, the fundamental problem when we do not observe a panel of households' choices is that we do not know how to connect the points across equilibria. Choice patterns could follow the dashed lines or the solid lines in the figure. However, a basic market clearing condition is that they must connect in some way: all households are in a house in each period, and all houses are occupied.

This basic insight suggests a way to bound welfare: simply search across all possible ways to "connect the dots" and find those that yield the lowest welfare estimate and the highest welfare estimate respectively. In particular, let $\mathcal{H}$ and $\mathcal{J}$ now be finite countable sets indexed by $h=\{1, \ldots, H\}$ and $i=\{1, \ldots, I\}$ with $H=I$. In Figure $2, H=2$, and there are two possibilities, the dashed lines or the solid lines. In general, there are $H$ ! ways to connect the dots between $H$ houses. However, this "search" can be solved with a simple linear program. Let $I_{h, h}$, be an indicator variable for whether some household (hypothetically) lived in house $h$ at $t=0$ and in house $h^{\prime}$ at $t=1$. We then have the following proposition.

Proposition 3. Under Assumptions A2-A4, a lower bound on aggregate welfare for a change in conditions, when prices, households, and landlords adjust to the change endogenously, can be found by solving the linear program:

$$
\operatorname{Min}_{\left\{I_{h, h^{\prime}}\right\}}\left[\sum_{h^{\prime}} \sum_{h} I_{h, h^{\prime}} \sum_{j} \frac{1}{2}\left(\left.\frac{\partial p^{0}}{\partial z_{j}}\right|_{\mathbf{z}_{h}^{0}}+\left.\frac{\partial p^{1}}{\partial z_{j}}\right|_{\mathbf{z}_{h^{\prime}}^{1}}\right)\left(z_{j, h^{\prime}}^{1}-z_{j, h}^{0}\right)-\sum_{h^{\prime}}\left(p_{h^{\prime}}^{1}-p_{h^{\prime}}^{1}\left(\mathbf{x}^{0}, \mathrm{~g}^{1}\right)\right)\right]
$$

such that

$$
\begin{aligned}
& \sum_{h} I_{h, h^{\prime}}=1 \forall h^{\prime} \\
& \sum_{h^{\prime}} I_{h, h^{\prime}}=1 \forall h .
\end{aligned}
$$

An upper bound can be found by instead maximizing the objective.

Proof: see the appendix.

Note the objective being minimized (or maximized) is the welfare approximation defined by Expression (9), simply changing the points of evaluation to an arbitrary pair $h, h^{\prime}$, multiplying by the indicator, and summing over both indices $h$ and $h^{\prime}$. The constraints represent the fact that each house is only chosen once at each point in time. 


\subsection{Identification using single-crossing}

An alternative to the bounds is to impose additional structure on the problem, namely a "single-crossing" restriction on any two households' indifference curves. If we additionally assume incomes are constant over time, then single crossing amounts to a restriction on preferences such that households' Marshallian marginal WTP functions for some observed amenity do not cross. That is, households can be ordered by their marginal WTP for the amenity, and the ordering will be the same evaluated at any level of the amenity and under any equilibrium price function. Because households always sort in the same order, if we have single crossing on $g$ then in Figure 2 we can infer that the sorting is that of the dashed lines, ruling out the solid lines. Essentially, the logic of single crossing provides a way to impute households' pattern of sorting, even when their actual locations are not observed. This property is formalized in Assumption A5:

Assumption A5 (Single Crossing). Let $V_{j i}\left(y_{i}, p(), z_{j}\right)$ be the indirect function conditional on one attribute $z_{j}$ given the price function $p()$, with the other attributes optimally chosen subject to $z_{j}, y$, and $p()$ to determine the utility level. Let $\mathcal{J}$ be a simply ordered set and let the distribution of demands be such that, for some amenity $z_{j}, v_{i}^{t} / \partial z_{j} \neq 0 \forall i$ and $\frac{\partial V_{j, i}\left(y_{i}, p(), z_{j}\right) / \partial z_{j}}{\partial V_{j, i}\left(y_{i}, p(), z_{j}\right) / \partial y}$ is everywhere non-decreasing in $i$. Furthermore, either $y_{i}$ is constant over time, or utility is quasi-linear in $y$.

Assumption A5 requires single crossing in only one dimension of the characteristic space, $z_{j}{ }^{8}$ A public good of particular interest like $g$ may be a natural choice for that attribute, but that choice is not necessary. It could be any characteristic or any scalar-valued index of characteristics. Even though we are modeling multidimensional characteristics, induced assortative matching along any one dimension is enough to impute households' choices. The single-crossing assumption, sometimes called the Spence-Mirrlees condition when written this way, guarantees that the level of $z_{j}$ chosen by households is always increasing in $i$. See, e.g., Milgrom and Shannon (1994) and Athey, Milgrom, and Roberts (1998 Ch. 3) for proofs. To see this intuitively, note that we could write A5 alternatively as follows. For any two households $i, i^{\prime}$ if $\frac{\partial V_{j, i}\left(y_{i}, \hat{p}(), \hat{z}_{j}\right) / \partial \hat{z}_{j}}{\partial V_{j, i}\left(y_{i}, \hat{p}(), \hat{z}_{j}\right) / \partial y} \geq$

\footnotetext{
${ }^{8}$ As Chiappori, McCann, and Nesheim (2010) discuss, extensions of the single-crossing property to the multi-attribute case lose the interpretation of inducing assortative matching. Although we are working with a multi-attribute model, Assumption 5 involves single-crossing of the WTP functions in the dimension of only one attribute, not multiple attributes.
} 
$\frac{\partial V_{j, i^{\prime}}\left(y_{i^{\prime}}, \hat{p}(), \hat{z}_{j}\right) / \partial \hat{z}_{j}}{\partial V_{j, i^{\prime}}\left(y_{i^{\prime}}, \hat{p}(), \hat{z}_{j}\right) / \partial y}$ for some $\hat{z}_{j}, \hat{p}()$, then $\frac{\partial V_{j, i}\left(y_{i}, p(), z_{j}\right) / \partial z_{j}}{\partial V_{j, i}\left(y_{i}, p(), z_{j}\right) / \partial y} \geq \frac{\partial V_{j, i \prime}\left(y_{i^{\prime}}, p(), z_{j}\right) / \partial z_{j}}{\partial V_{j, i}\left(y_{i^{\prime}}, p(), z_{j}\right) / \partial y}$ for all $z_{j}$, $p()$. Thus, if a household selects more $z_{j}$ than another household in the baseline scenario, it will do so in the ex post scenario as well. ${ }^{9}$ However, this requires ruling out income effects.

All this suggests a simple approach for identifying Expression (9) without panel data on households. Let $F_{j}^{t}$ ( ) be the distribution function of some continuously distributed amenity $z_{j}$ at time $t$. Given that $z_{j}$ is continuously distributed, for each observed percentile $\theta \in\{1 / H, 2 / H, \ldots$, 1 ) of the distribution of $z_{j}$, there will be a unique vector $\mathbf{z}^{t}(\theta)$ at $t$. Let $z_{k}^{t}(\theta)$ be the value of the $k^{\text {th }}$ attribute of this vector. Note that for $k=j, z_{k}^{t}(\theta)=\left(F_{j}^{t}\right)^{-1}(\theta)$. Then we can now state the following proposition.

Proposition 4. Under Assumptions A2-A5, aggregate welfare for a change in conditions, when prices, households, and landlords adjust to the change endogenously, can be computed from observed prices and estimated derivatives as follows:

$$
\begin{aligned}
d W \approx \sum_{\theta} \sum_{k} \frac{1}{2}\left(\frac{\partial p^{0}}{\partial z_{k}}\left|\mathbf{z}^{0}(\theta)+\frac{\partial p^{1}}{\partial z_{k}}\right| \mathbf{z}^{1}(\theta)\right)\left[z_{k}^{1}(\theta)-z_{k}^{0}(\theta)\right] \\
-\sum_{h}\left(p_{h}^{1}-p_{h}^{1}\left(\mathbf{x}^{0}, \mathrm{~g}^{1}\right)\right)
\end{aligned}
$$

Proof: Consider the initial equilibrium described by the hedonic price function $p^{0}(g, \mathbf{x})$. For any $\theta \in[1 / H, 2 / H, \ldots, 1]$, consider a household which chooses $z_{j}$ in the initial equilibrium such that $F_{j}^{0}\left(z_{j}\right)=\theta$. By Assumption A5 (single crossing), when facing the new equilibrium price function $p^{1}(g, \mathbf{x})$, the household would choose $z_{j}$ such that $F_{j}^{1}\left(z_{j}\right)=\theta$. The remainder follows by Proposition 2, simply evaluating each household at the $\mathbf{z}$ corresponding to a constant percentile of the distributions of $z_{j}$.

Proposition 4 states that one can rank the houses by one amenity $z_{j}$ in each scenario, find the change in all attributes at a constant percentile of the $z_{j}$ distribution, and evaluate the derivatives of the hedonic price function at the $\mathbf{z}$ falling at this percentile of the $z_{j}$ distribution. The final term is the same price adjustments as in Expression (9). In practice, note that as long as one knows the

\footnotetext{
${ }^{9}$ Intuitively, given that the Marshallian demand functions do not cross, this obviously must be so if the implicit price of $z_{j}$ is increasing in $z_{j}$ (i.e. if the hedonic price function is convex in $z_{j}$ ). However, even if the implicit price is decreasing in $z_{j}$ over portions of the range, the second-order condition for utility maximization requires that it cut the demand curves from below. In other words, the economics of the model require that the slope of the price function be greater than the slope of the demand curve in the neighborhood of the optimal choice. Thus, households will always "sort" across $z_{j}$ in the same order, even if they are changing consumption of other attributes or the numeraire.
} 
attributes at all locations and time periods, this estimate can be implemented with only a repeated cross section of housing prices (i.e. without a full panel): all that is required is that $p^{1}$ and $\frac{\partial p^{t}}{\partial z_{j}}$ can be predicted for each house from the hedonic pricing model.

This single-crossing condition is routinely imposed in the literature on non-linear pricing (e.g. Athey, Milgrom, and Roberts 1998, Wilson 1993), including models of monopoly screening as well as locational sorting. Although imposing this property is undoubtedly a restriction relative to the more general treatment up to this point, it is actually less restrictive in this respect than many structural models, which employ the same single crossing property plus additional functional form restrictions or parametric restrictions on the distribution of unobservable demand shifters. For example, consider the common class of models which allow households $i$ to differ in two dimensions, income $y$ and a parameter $\alpha$ reflecting tastes for $g$. Many hedonic and sorting applications, including Bajari and Benkard (2005), Heckman, Matzkin, and Nesheim (2010b), and Bishop and Timmins (2019) impose the additional restriction that WTP is strictly increasing in $\alpha$ and that preferences are quasi-linear. These models implicitly impose Assumption A5: households are totally ordered by $\alpha$, with increasing $\alpha$ implying increasing $g$.

This is not to say that all papers impose these conditions. Other models impose only a partial ordering on $i$ rather than a total ordering. For example, Sieg et al. (2004), Epple, Peress, and Sieg (2010), and Kuminoff (2012) order households by $\alpha$ conditional on $y$, and vice versa. However, pairs of households where one has higher $\alpha$ and the other higher $y$ need not be ordered: one household may choose higher $g$ than the other household in one equilibrium but not necessarily in another equilibrium. In this sense, Assumption A5 is stronger than the related single crossing assumptions imposed in those papers. However, in other respects the approach of this section still imposes weaker assumptions about heterogeneity. Sieg et al. (2004), Epple, Peress, and Sieg (2010), and Kuminoff (2012) compensate for their weaker single crossing assumptions by imposing additional functional form restrictions on $v()$ and/or parametric assumptions on the joint distribution of $(\alpha, y)$.

Of course, single crossing is only a modeling assumption. In practice, Expression (11) may be a reasonable approximation to Expression (9) even when households are not truly totally ordered, in violation of Assumption A5. In the simulations reported in Section 7, the matching-bypercentiles approach of Expression (11) gives results quite close to the matching-by-households 
approach of Expression (9), even when households are not totally ordered. To see why, note that if the hedonic price functions were linear, so that marginal prices were constant, then any matches would give the same aggregate welfare measures, namely the average of the two marginal values times the sum of changes in the attributes. So, when single crossing does not hold, even if households do not sort in exactly the same order in different scenarios, their rank orderings are still correlated. Consequently, violations of Assumption A5 create errors in the imputation of $z$ that are only local. If the hedonic price functions is approximately linear over the range of the errors, then the errors offset (with area A approximately equal to area B in Figure 2). In this sense, estimates based on Expression (11) can be thought of as approximations to Expression (9).

\subsection{Matching by group}

Whereas Section 3 assumed complete knowledge about where individual households sort over time in the product space, this section so far has assumed no knowledge about that whatsoever. In between these two cases are a variety of intermediate ones where partial information is available on the households locating at a house. Such partial information would allow us to either further restrict the bounds of Section 4.1 by ruling out some possible matches, or alternatively to partially relax the single-crossing assumption of Section 4.2.

For example, suppose we can track where types of households live but not the individual household. Perhaps we can observe the race of a household occupying a given house, or its income, or some other characteristic or combination of characteristics. Then the bounds of Section 4.1 can be tightened by imposing the additional restriction that $I_{h, h^{\prime}}=0$ whenever the observed characteristics of households at $h$ in $t=0$ and $h^{\prime}$ in $t=1$ do not correspond.

Alternatively, the structure imposed in Section 4.2 can be relaxed, as we would now only require that the single crossing property hold within observable type. In particular, the required single-crossing condition may be modified as follows.

Assumption A5' (Single crossing within type). Let $\mathcal{T}$ be a set of observable types which partitions the set of households $\mathscr{K}$. Let $\tau \subset \mathcal{T}$ be the set of households of a specific type with measure $\mu_{\tau}, \sum_{\tau} \mu_{\tau}=1$, and let each $\tau$ be a simply ordered subset of the partially ordered set $\mathcal{J}$. For each $\tau$, let the distribution of demands be such that, for some amenity $z_{j}$, at fixed $y_{i}$, $\frac{\partial V_{j, i}\left(y_{i}, p(), z_{j}\right) / \partial z_{j}}{\partial V_{j, i}\left(y_{i}, p(), z_{j}\right) / \partial y}$ is everywhere nondecreasing in $i \in \tau$.

This property guarantees that, after conditioning on the observed type, households sort along $z_{j}$ in 
the same order. Thus, if a household selects more $z_{j}$ than another household of the same type in the baseline scenario, it will do so in the ex post scenario as well. This approach allows households to be partially ordered overall but totally ordered within type, as in the Epple-Sieg approach, where households are totally ordered after conditioning on income.

In this case, Expression (11) can be modified as follows. Let $I_{\tau}$ be the number of observed households of type $\tau$ and let $\theta_{\tau}=\left\{1 / I_{\tau}, 2 / I_{\tau}, \ldots, 1\right\}$ be the observed percentiles of the distribution of $z_{j}$ among type $\tau$. Then by the same argument as given in Proposition 4, aggregate welfare is

$$
\begin{aligned}
& d W \approx \sum_{\tau \in \mathcal{T}} \frac{\mu_{\tau}}{I_{\tau}} \sum_{\theta_{\tau}} \sum_{k} \frac{1}{2}\left(\frac{\partial p^{0}}{\partial z_{k}}\left|\mathbf{z}^{0}\left(\theta_{\tau}\right)+\frac{\partial p^{1}}{\partial z_{k}}\right| \mathbf{z}^{1}\left(\theta_{\tau}\right)\right)\left[z_{k}^{1}\left(\theta_{\tau}\right)-z_{k}^{0}\left(\theta_{\tau}\right)\right] \\
&-\sum_{H}\left(p_{h}^{1}-p_{h}^{1}\left(\mathbf{x}^{0}, \mathrm{~g}^{1}\right)\right)
\end{aligned}
$$

That is, for each type, one can take the set of houses occupied by that type and rank them by $z_{j}$ in both scenarios, find the change in $z_{k}$ at a constant percentile of the distribution, and evaluate the derivatives of the hedonic price function at the same percentile of the distribution. Then, one can take the weighted sum over types. Moreover, if the type is observed income, then we no longer need to rule out income effects, as we can condition on them.

\section{Transactions Costs}

So far, we have assumed that there are no transactions costs from re-optimizing (Assumption A2). This assumption may be most fitting for consumer goods such as computers (Bajari and Benkard 2005) or groceries (Griffith and Nesheim 2013), which are purchased regularly. For applications to housing or to labor markets, the transaction costs of moving homes or changing jobs may be much higher.

With transactions costs, Propositions 1 and 2 are no longer valid, because the first-order condition of utility maximization represented by Equation (1) no longer need hold in both periods (see Bishop and Murphy 2019 for discussion). Instead, the transactions costs create a wedge, turning the equalities of Equation (1) into inequality constraints.

However, we can still bound the results. First, return to the case where Assumption A1 holds, so we observe whether households move or not. In addition, suppose that households my- 
opically optimized in the baseline period (without anticipating changes). Finally, suppose the analyst has an estimate of the average moving cost among those who actually move, MC. (Alternatively, we can always make what-if statements along the lines of: "if average moving costs are $M C$, then the bounds would be such-and-such.")

For movers, we then can still use Propositions 1 or 2 to form point estimates of their welfare, subtracting out aggregate moving costs, which is $M C$ times the number of movers. For nonmovers, when conditions improve, we can create an upper bound on compensating variation by assuming constant marginal WTP from the baseline condition. Essentially, this uses a rectangle instead of the trapezoid. By the same token, for non-movers we can create a lower bound of zero. When conditions worsen instead of improve, the rectangle at baseline marginal WTP is now a lower bound on damages. Adding up the welfare for the movers and non-movers creates a bound for the whole group. The bound involves a mix of first-order approximations and second-order approximations suited to the situations observed.

If, instead of being myopic, households are forward-looking, then the recent results of Bishop and Murphy (2019) apply. They develop a model in which households make a single choice of a house to which they're committed. Households maximize expected utility at the house, given the current price functions and expectations about future amenities. To see the connection between the Harberger approximation and their results, suppose, momentarily, that households are not only forward-looking but perfectly prescient about the future and, furthermore, that WTP functions for amenities are linear. Then, in the model of Bishop and Murphy, households would set an average of (discounted) marginal WTP over time equal to the marginal hedonic price at the time of purchase, and Lemma 1 above would hold exactly if we applied a discount rate to the second period terms. Essentially, the conditions holding across two time periods with no transactions cost are the same as the conditions that hold at a single point in time when there are transactions costs. As Bishop and Murphy show, when households are not perfectly prescient but still right "on average," the hedonic estimate would still be unbiased when amenities are increasing or decreasing. They further show that when WTP functions are non-linear, there is a bias from a static hedonic model. The results of this paper can be applied to their bias term to suggest that the bias is thirdorder.

Next, relax Assumptions A1 and A2, so that there are moving costs and we do not observe 
household movements. Unfortunately, the lower bound from the linear program of Proposition 3 is no longer valid, because with moving costs we can no longer assume that the quantities demanded even trace out a demand curve at all, even the demand curves implied by the lower-bound algorithm.

However, the upper bound from Proposition 3 does remain valid. The intuition here is simple: By Proposition 3, the expression is an upper bound on welfare when there are no moving costs. Because moving costs can only reduce the true welfare of a change in the economic environment, the expression remains an upper bound. This result is quite general.

Moreover, it may be possible to find tighter bounds. In particular if a household is assumed to move from $h$ to $h^{\prime}$, it must be that they are willing to pay the transactions cost to move to $h^{\prime}$ rather than stay in $h$ under the new conditions, given the preferences implied by the move from $h$ to $h^{\prime}$. Accordingly, if we know individual MC (or assume homogeneous moving costs), we can impose the additional restriction in the linear problem associated with Proposition 3:

$$
\begin{gathered}
I_{h, h^{\prime}}\left[\sum _ { j } \left(\left.\frac{1}{2} \frac{\partial p^{1}}{\partial z_{j}}\right|_{\mathbf{z}_{h^{\prime}}}+\frac{1}{2}\left(\left.\frac{\partial p^{1}}{\partial z_{j}}\right|_{\mathbf{z}_{h^{\prime}}^{1}}+\frac{\left.\frac{\partial p^{1}}{\partial z_{j}}\right|_{\mathbf{z}_{h^{\prime}}^{1}}-\left.\frac{\partial p^{0}}{\partial z_{j}}\right|_{\mathbf{z}_{h}^{0}}}{z_{j, h^{\prime}}^{1}-z_{j, h}^{0}}\left(z_{j, h \prime}^{1}-z_{j, h}^{1}\right)\right)\left(z_{j, h^{\prime}}^{1}-z_{j, h}^{1}\right)\right.\right. \\
\left.-\left(p_{h^{\prime}}^{1}-p_{h}^{1}\right)-M C\right] \geq 0 \forall h, h^{\prime} \neq h
\end{gathered}
$$

The ratio $\left(\left.\frac{\partial p^{1}}{\partial z_{j}}\right|_{\mathbf{z}_{h^{\prime}}^{1}}-\left.\frac{\partial p^{0}}{\partial z_{j}}\right|_{\mathbf{z}_{h}^{0}}\right) /\left(z_{j, h^{\prime}}^{1}-z_{j, h}^{0}\right)$ gives the slope of the demand curve implied by the move from $h$ at $t=0$ to $h^{\prime}$ at $t=1$. The terms $\left.\frac{\partial p^{1}}{\partial z_{j}}\right|_{\mathbf{z}_{h^{\prime}}^{1}}$ and the large term in parentheses are the height of this demand curve evaluated respectively at $h^{\prime}$ and $h$ at $t=1$. Multiplying by the actual difference in $z$ and subtracting the price difference gives the consumer surplus. Multiplying by $I_{h, h^{\prime}}$, this restriction insures that either $I_{h, h^{\prime}}=0$, or else the consumer surplus of moving from $h$ to $h^{\prime}$ exceeds transactions costs. 


\section{When Preferences Shift}

In all the models to this point, we have relied on Assumption A3, that households' preferences are constant over the time period considered, so that a household's optimal choice of the vector $\mathbf{z}$ is an unchanging functional of the hedonic price function and income. As with Assumption A2 (moving costs), Assumption A3 may be most fitting for hedonic applications to consumer goods such as computers or groceries. It may be less fitting for applications to housing if taste changes are important in that context or, to put it differently, when there are important changes in parameters affecting current-period utility, such as family status. In such cases, even when we observe points for two equilibria for a single household (Section 3), they may be on two different utility functions. Likewise, even if household preferences exhibit the single crossing property (Section 4), if preferences are shifting then there is no reason to believe households are still sorting in the same order.

In this section, I consider relaxing Assumption A3 as well as Assumption A1. That is, we do not observe a panel of households and, moreover, an individual's household's WTP for attributes may be changing anyway. Such changes in demands of course will have implications for equilibrium hedonic prices. But more importantly, they raise fundamental questions about what perspective to take when evaluating changes in conditions (Stapleford 2009). I take the approach of Fisher and Shell (1972) and Pollak (1989), who suggest that welfare comparisons can be made in such situations from the perspective of one or the other of the two preference relationships. This basic approach also is implicit in simulation exercises such as those in Sieg et al. (2004), Bayer et al. (2011), or elsewhere, where general equilibrium welfare effects are estimated for policy shocks under an assumption of constant preferences, even though preferences may well change over the time periods envisioned. Essentially, these simulations evaluate the policy shocks from the perspective of ex ante preferences.

From this perspective, we can again use the single crossing property along with a weaker version of Assumption A3:

Assumption A3'. The distribution of pairs $\left(v^{t}(), y^{t}\right)$ is the same as it would have been if $v()$ were constant. Consequently, the distribution of demand functionals $\mathbf{z}\left(p^{t}()\right)$ is the same.

Assumption A3' is implied by A3 but not the reverse. It says that although individual households' demand functions may change over time, the distribution of demand types remains constant. This assumption is probably most valid for short time windows, such as those considered by Figlio 
(2004), Lucas (2004), or the 1999-2000 change in crime recently considered by Bishop and Timmins (2019).

With this weaker assumption, all the results of Section 4 flow through, but now interpreting the result as the welfare measure from the perspective of a single time period. For example, when single crossing holds, we can now state Proposition 5.

Proposition 5 Under Assumptions A2, A3' and A4-A5, aggregate welfare for a change in hedonic conditions, evaluated from the perspective of constant preferences for each household, can be computed from observed prices and estimated derivatives as given by Equation (11). Moreover, the aggregate evaluation is the same whether using ex ante or ex post preferences (though the distributional effects may be different).

Proof: See the appendix.

Proposition 5 says that we can still use the same measure for aggregate welfare as given in Proposition 4 under a weaker version of Assumption A3, in which individual household demands may shift due to changes in preferences or incomes, as long as the distribution of demands does not change. However, the welfare estimates are now from a single period perspective, or alternatively are counterfactual estimates "as if" preferences had remained constant.

The intuition of Proposition 5 is fairly straightforward. We wish to estimate welfare "as if" preferences had not changed between periods. However, if the joint distribution of preferences and incomes are the same as if preferences hadn't changed, the observed equilibria are the same as they would have been under the missing hypothetical. Therefore, any welfare measures we construct from the observed equilibria are consistent with what we'd want under the missing hypothetical.

Moreover, if single crossing is considered too strong an assumption, we can still construct the bounds of Section 4 by the same argument.

\section{Illustrative Simulations}

In this section I illustrate the results from the previous two sections using simulated data, which allows us to compare the constructs to "true" welfare values. In particular, I simulate 100 hedonic housing equilibria, each with 1000 households and 1000 houses. Households sort over two variables, a lot of fixed size with an exogenously supplied amenity $g$, which is shocked between two time periods, and housing capital $x$, which is sold endogenously by suppliers. Households update 
their purchase of $x$ between scenarios.

The public good $g$ is uniformly distributed on $(1,3)$ in the baseline scenario. In the ex post scenario, one-third of the houses are treated by a policy. If a house is treated, its level of $g$ improves such that $g^{1}=g^{0}+\left(3-g^{0}\right) / 3+1$. Panel A of Figure 3 illustrates the levels of $g$ in one representative simulation. It shows the cumulative distribution functions (CDF) of $g$ in each scenario, indicating that the ex ante scenario is uniformly distributed, while the ex post scenario, which $1^{\text {st }}$-order stochastically dominates it, is not.

I use two functional forms for utility. First, I use a functional form introduced by Epple and Sieg (1999), variants of which have been used by Sieg et al. (2004), Epple, Peres, and Sieg (2010), Kuminoff (2012), and others. In particular, indirect utility is given by:

$$
V=\left\{\alpha g^{\rho}+\left[\mathrm{e}^{\frac{(y-p(\mathrm{~g}))^{1-v}-1}{1-v}} \mathrm{e}^{-\frac{\beta p_{\chi}^{\eta+1}-1}{\eta+1}}\right]^{\rho}\right\}^{\frac{1}{\rho}}
$$

where $y$ is income, $p(g)$ is the hedonic price of a lot with public good $g$, $p_{x}$ is the supply-price of $x, \alpha$ is an individual-specific taste parameter for $g$, and $\beta, \eta, v$, and $\rho$ are additional parameters. This indirect utility function has no closed form for utility, but one can interpret it as involving a constant-elasticity of substitution between private and public goods, and a constant income and price elasticity of demand for $x$. With this model, demand for $x$ is independent of $g$, except through the effect of $g$ on prices. I set $\beta=3, \eta=-0.963, v=0.75$, and $\rho=-0.02$. I let income be distributed log-normal with $\mu_{y}=11.1$ and $\sigma_{y}=0.4$ (and truncated at $\$ 25,000$ and $\$ 200,000$ ). Finally, I let $\alpha$ be log-normal with $\mu_{\alpha}=-0.25$ and $\sigma_{\alpha}=0.97$. Single crossing does not strictly hold in this model, though it holds in $\alpha$ conditional on $y$ and vice versa.

Second, I use the cross-packaging model, discussed and analysed by von Haefen (2007). In particular, I assume indirect utility is given by:

$$
V=\frac{y-p(\mathrm{~g})+\theta \ln (\mathrm{g})}{\exp \left[\frac{\exp (\alpha+\delta \mathrm{g}) p_{x}^{1+\beta}}{1+\beta}\right]}
$$


In this model, $g$ enters utility in two places. It enters as an additively separable term in the numerator. It also enters in the denominator, in a term that shifts the demand for $x$. In particular, the demand for $x$ is given by:

$$
x^{*}=\alpha+\beta \ln (p)+\ln (y)+\delta g \text {. }
$$

Thus, $g$ is valued directly as well as indirectly through increasing the consumer surplus for $x$. I let $\alpha \sim \mathrm{u}(-2.2,-1.8), \beta=-1.1, \theta \sim \mathrm{u}(750,1050)$, and $\delta$ distributed triangular with points $(0.004,0.006$, 0.012). Income is distributed as before. These parameters are calibrated so that the median marginal willingness to pay for $g$ is approximately equal to that from the first model.

Given the distribution of $g$ and of household characteristics, market-clearing prices were solved for, along with equilibrium levels of the endogenous characteristic $x$, for each of the 100 simulations and for each utility function. Panel B of Figure 3 shows land prices, after netting out the value of capital $x$, for one representative scenario using the Epple-Sieg utility function. It shows that price levels increased in the ex post scenario. However, as scene in Panel C, marginal prices (or marginal WTP) for $g$ fell in the ex post scenario, largely because of the increased supply of $g$. The marginal price function is quite convex, with an extremely sharp up-turn in the righthand tail.

Equilibrium prices in each scenario were then perturbed by an error term, normally and independently distributed and calibrated such that the standard deviation of the error was equal to $1 \%$ of the mean price. This error term can be interpreted as either measurement error in price (the dependent variable) or as an unobserved characteristic of the home that enters preferences as a perfect substitute for the numeraire good.

Hedonic price functions were fitted to this noisy data using three methods. The first uses semi-parametric methods, partially out $x$ using linear regression and estimating the residual price as a function of $g$ using quadratic local regressions. The second uses a fifth-ordered polynomial function. The third uses a translog function, regressing logged prices on logs of $g$ and $x$, their squares, and an interaction. Figure 4 shows the estimated partial derivatives with respect to $g$, plotted against the true marginal WTP, for one representative simulation, for both the ex ante and ex post scenarios, for the Epple-Sieg utility function. The local regression and the polynomial are able to fit the data over most of the support, but badly under-predict in the right-hand tail, as they 
cannot fit the sharp turn seen in Figure 3C. Nevertheless, those mistakes are over a range of the data with little density, so the functions capture mean marginal values well. The translog function does a much poorer fit overall, finding some negative values at low levels of $g$. It also does a poor job of adjusting for changes in $x$. The equilibrium value of capital is separable in this model, but the $\log$ transformation forces interactions in the value of $g$ and $x$.

Finally, from these price functions and their derivatives, true welfare measures and the empirical approximations were computed. Table 1 reports the results for baseline models, with no transactions costs. The table shows mean values across the 100 simulations, as well as the $5^{\text {th }}$ and $95^{\text {th }}$ percentiles across simulations. The first two rows show the Hicksian CV and EV for the improvement to $\mathrm{g}$. $\mathrm{EV}$ is lower than $\mathrm{CV}$ in these scenarios because of the increase in prices, which actually puts households on lower indifference curves. (However, net welfare still increases because these price increases are income to landlords.) The difference between EV and CV is greater for the Epple-Sieg model at these parameter values.

In the third row, the table shows the value of Equation (9), when households can be tracked over time. The first column computes the expression using the true marginal values from the utility function. It shows that the second-order approximation falls between EV and CV, as expected. The next columns compute the expression using the derivatives from the three respective estimated price functions. With both utility functions, the semi-parametric and polynomial gradients do quite well, giving values close to those using the true marginal values and close to the range of EV and $\mathrm{CV}$. The translog function badly overstates the values.

The remaining rows show the results from Section 4, which is applicable when households cannot be tracked over time. The first two rows give the lower and upper bound respectively, using a linear program to find the allocations over time that respectively minimize and maximize total welfare. By construction, the values bracket those using Equation (9). They also bracket the true EV and $\mathrm{CV}$, with a reasonable range, again except for the translog function. The final row shows the results when consumption patterns over time are imputed using the single crossing property. Although the Epple-Sieg utility function does not impose single-crossing globally, households tend to sort in similar patterns over time. As a consequence, the errors from imposing single crossing tend to be small and to cancel out. The welfare estimates using this imputation are almost exactly the same as those constructed under the assumption that we can actually track households 
over time.

To explore the reasons for this result, Figure 5 illustrates the sorting patterns observed in one illustrative simulation. The first panel shows the level of $g$ households choose in the ex post scenario, against the marginal WTP for $g$ of each household evaluated at the "average house." That is, it shows the household's optimal $g$ as a function of an index of its demand-type for $g$. If bid functions never crossed, this figure would show an increasing function. While it is not strictly increasing, it is nearly so, indicating the any crossings in the bid functions are only very local. The second panel shows the households' level of $g$ in the ex post scenario versus the ex ante scenario. It illustrates that households sort approximately in the same order, though not exactly. Finally, the third panel shows the level of $g$ imputed for a household in the ex post scenario using singlecrossing, against its actual level of $g$ in the scenario. It shows that the errors from imposing the single-crossing assumption are fairly small. Consequently, the hedonic price function is approximately linear over the range of these errors, and the overall bias is minimal. Thus, even when household sorting is not observed, and even when the single crossing property does not truly hold, models based on this property potentially can still be quite useful.

Tables 2A and 2B report the results from imposing transactions costs in the equilibrium. In particular, from an initial optimal point, households adjust to the shock in $g$ subject to a moving cost annualized to be $\$ 200$ and $\$ 400$ respectively in the two tables, which, at a 5\% discount rate, equate to one-time costs of $\$ 4,000$ and $\$ 8,000$. The true $E V$ and $C V$ are lower in these scenarios, as households can no longer take advantage of the shock by re-optimizing as easily, and as real resources are used up on transactions. Moreover, Equation (9) is no longer valid, as there is now a wedge between the hedonic gradient and marginal values. As shown in the tables, the expression gives values that now fall outside the range of $\mathrm{EV}$ and $\mathrm{CV}$.

However, as discussed in Section 5, when we can track households, we can bound the true values using a mix of first-order approximations for non-movers and Equation (9) for movers (net of transactions costs). The fourth and fifth rows of the table show these results. Finally, when households are not observed over time, we can still use the upper bound from Section 4, and even tighten it somewhat by requiring the gain from any move to exceed transactions costs. The final two rows in the table illustrate these bounds. The bounds are fairly tight in the simulations using the Epple Sieg utility function, but are somewhat higher using the repackaging model. 


\section{Empirical Application and Comparison}

To illustrate how the methods introduced in this paper can be used on real-world data, and to compare the results to estimates from other structural models, I apply the methods to data previously studied by Bishop and Timmins (2019). They consider the value of reductions in violent crime in the San Francisco area between 1999 and 2000. Over that period, average violent crime rates fell by about $1.7 \%$, though they increased at about one-third of housing locations.

Using housing data from 1994-2000, Bishop and Timmins estimate hedonic gradients for crime, first partialling out the effects of structural characteristics, then estimating the gradient for crime using local polynomial regression. They then estimate demand curves using Rosen's (1974) two-step method, regressing marginal values from the first-stage price function on the level of crime plus household level variables, including income and race, and year dummies (interpreted as annual demand shifters). They also introduce a new maximum likelihood method in the spirit of Heckman et al. (2005). This approach involves parameterizing utility, including unobserved heterogeneity, and re-writing the problem to isolate the unobserved heterogeneity as a function of marginal prices, crime and other observables, and the parameters. Values of the parameters that maximize the likelihood can then be computed. See Bishop and Timmins (2019) for details.

Households are not tracked over time in these data. However, using the hedonic gradients and crime levels, one easily can compute the values of Equation (11), using the single crossing assumption. One need only sort the data by the 1999 crime level (or other attribute), then by the 2000 crime level, and merge the data back together. Averaging the 1999 and 2000 gradients and multiplying by the change in crime gives the value of Equation (11). ${ }^{10}$ Table 3 gives the results. The average value for the shift from the 1999 equilibrium to the 2000 equilibrium, including both the change in crime and the shift in the hedonic price function, is \$236. As discussed in Section 4, instead of imposing single crossing, one can solve the linear program to bound the possible values. The bounds using this approach are \$235 to \$568. Interestingly, in this application the singlecrossing approach identifies a point quite near the lower bound, unlike with the above simulations. In general, where the single crossing estimate fits within the bounds will depend on the correlations between changes in marginal prices and changes in amenities in the data.

\footnotetext{
${ }^{10}$ Because the price effect of $\mathbf{x}$ is assumed to be linear, the terms involving it in Expression (11) cancel.
} 
These results can be adjusted to make them more comparable to the results of Bishop and Timmins (2019). In particular, Bishop and Timmins estimate a shift in demand for amenities between 2019 and 2000 and then net out that shift in their welfare estimates (evaluating changes from the 2019 perspective, not unlike the proposal in Section 6 above). They also cut off changes in crime at a point where their estimated marginal willingness to pay falls to zero. For comparison purposes, I adjust the 2000 marginal values downward by their estimated 2019-20 difference in marginal values and use the same change in crime as they use after censoring. These adjusted values are shown in the next three rows of the table. The average values fall by about $\$ 50$.

Interestingly, these adjusted values are quit close to those using the more structural approach of Rosen (1974), as reported by Bishop and Timmins (2019). This suggests it may be possible to approximate the results from more structural approaches using much simpler, reduced form methods. Whereas the approach based on Equation (11) matches marginal values over time based on a single crossing assumption, Rosen's approach essentially matches them over time by matching on observed demographics. In this case, the results are quite similar. On the other hand,

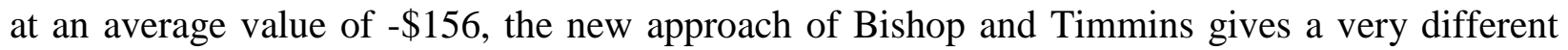
value. They find very negative values for the one-third of households who experience an increase in violent crime, which more than offset the gains to other households. This difference is most likely because the two approaches answer different questions. Whereas the approach suggested in this paper values a change between general equilibria, including price changes, their approach isolates the partial equilibrium value of a change in crime, netting out price effects. ${ }^{11}$

\section{Conclusions}

For decades, economists have used the hedonic model to estimate demands for the implicit characteristics of differentiated commodities, including the demands for otherwise unpriced local public goods and amenities. The traditional cross-sectional approach to hedonic estimation has recovered marginal WTP for amenities when unobservables are conditionally independent of the amenities, but has faltered over a difficult endogeneity problem when attempting non-marginal welfare measures. In this paper, I show that when marginal prices can be reliably estimated, and when panel data on household sorting is available, one can construct an approximation-using only the first-stage marginal prices-which is a "sufficient statistic" for non-marginal welfare measures.

\footnotetext{
${ }^{11}$ An additional difference is that I use only 1999-2000 data, whereas they use the full 1994-2000 data set.
} 
With this approximation, Rosen's second-stage estimation can be replaced with a simple average of first-stage parameters.

Moreover, even when panel data on household sorting are unavailable, the sufficient statistic approach can be used to create bounds on the welfare measures using only repeated cross sections of housing data. Alternatively, point identification can be established using a single crossing restriction. In practice, this approximation appears to perform well in these simulations even when this restriction does not strictly hold.

Future work might consider hybrids between the approach taken here and other work. Perhaps the approach introduced here could be used to model baseline heterogeneity, while more structural approaches could be introduced to model changes in preferences, semi-parametrically. Perhaps it could be combined with quasi-experimental methods for identifying the hedonic price function in panel data settings (Kuminoff and Pope 2014, Banzhaf 2018). Finally, perhaps it can be combined with dynamic models to approximate or bound welfare when households anticipate future changes (Bishop and Murphy 2019). 


\section{References}

Athey, S., P. Milgrom, and J. Roberts. 1998. Robust Comparative Statics. Draft monograph available at scholar.harvard.edu/files/athey/files/draftmonograph98.pdf.

Bajari, P., and L. Benkard. 2005. Demand Estimation with Heterogeneous Consumers and Unobserved Product Characteristics: A Hedonic Approach. Journal of Political Economy 113(6): 1239-76.

Banzhaf, H.S. 2005. Green Price Indices. Journal of Environmental Economics and Management 49(2): 262-80.

Banzhaf, H.S. 2010. The Chicago School of Welfare Economics. In The Elgar Companion to the Chicago School of Economics, ed. by R. Emmett. Cheltenham, UK: Elgar, pp. 59-69.

Bartik, T.J. 1987. The Estimation of Demand Parameters in Hedonic Price Models. Journal of Political Economy 95(1): 81-8.

Bartik, T.J. 1988. Measuring the Benefits of Amenity Improvements in Hedonic Price Models. Land Economics 64(2): 172-83.

Bayer, P., M.D. Casey, F. Ferreira, and R. McMillan. 2012. Estimating Racial Price Differentials in the Housing Market. NBER working paper 18069.

Bayer, P., F. Ferreira, and R. McMillan. 2007. A Unified Framework for Measuring Preferences for Schools and Neighborhoods. Journal of Political Economy 115(4): 588-638.

Bayer, P., R. McMillan, A. Murphy, and C. Timmins. 2016. A Dynamic Model of Demand for Houses and Neighborhoods. Econometrica 84: 893-942.

Bishop, K.C. 2012. A Dynamic Model of Location Choice and Hedonic Valuation. Mimeo.

Bishop, K.C., and A.D. Murphy. 2019. Valuing Time-Varying Attributes Using the Hedonic Model: When is a Dynamic Approach Necessary? Review of Economics and Statistics 101(1): 134-45.

Bishop, K.C., and C. Timmins. 2018. Using Panel Data to Easily Estimate Hedonic Demand Functions. Journal of the Association of Environmental and Resource Economists 5(3): 51743.

Bishop, K.C., and C. Timmins. 2019. Estimating the Marginal Willingness to Pay Function without Instrumental Variables. Journal of Urban Economics 109: 66-83.

Chetty, R. 2009. Sufficient Statistics for Welfare Analysis: A Bridge between Structural and Reduced-Form Methods. Annual Review of Economics 1: 451-88.

Chiappori, P.-A., R.J. McCann, and L.P. Nesheim. 2010. Hedonic price equilibria, stable matching, and optimal transport: equivalence, topology, and uniqueness. Economic Theory 42(2): 317-54.

Davis, L.W. 2004. The Effect of Health Risk on Housing Values: Evidence from a Cancer Cluster. American Economic Review 94(5): 1693-1704. 
Ekeland, I., J.J. Heckman, and L. Nesheim. 2004. Identification and Estimation of Hedonic Models. Journal of Political Economy 112(1): S60-S109.

Epple, D. 1987. Hedonic Prices and Implicit Markets: Estimating Demand and Supply functions for Differentiated Products. Journal of Political Economy 95(1): 59-80.

Epple, D., M. Peress, and H. Sieg. 2010. Identification and Semiparametric Estimation of Equilibrium Models of Local Jurisdictions. American Economic Journal: Microeconomics 2(4): 195-220.

Epple, D., and H. Sieg. 1999. Estimating Equilibrium Models of Local Jurisdictions. Journal of Political Economy 107(4): 645-81.

Figlio, D.N., and M.E. Lucas. 2004. What's in a Grade? School Report Cards and the Housing Market." American Economic Review 94: 591-604.

Fisher, F.M., and K. Shell. 1972. Taste and Quality Change in the Pure Theory of the True Costof-Living Index. Essay I in The Economic Theory of Price Indices. New York: Academic Press.

Griffith, R., and L. Nesheim. 2013. Hedonic Methods for Baskets of Goods. Economics Letters 120: 284-87.

Harberger, A. C. 1971. Three Basic Postulates for Applied Welfare Economics: An Interpretive Essay. Journal of Economic Literature 9(3): 785-97.

Heckman, J.J. 2010. Building Bridges Between Structural and Program Evaluation Approaches to Evaluating Policy. Journal of Economic Literature 48(2): 356-98.

Heckman, J.J., R.L. Matzkin, and L. Nesheim. 2005. Simulation and Estimation of Hedonic Models. In Frontiers in Applied General Equilibrium, ed. by T. Kehoe, T.N. Srinivasan, and J. Whalley. Cambridge: Cambridge University Press.

Heckman, J.J., R.L. Matzkin, and L. Nesheim. 2010a. Nonparametric Estimation of Nonadditive Hedonic Models. Econometrica 78(5): 1569-91.

Heckman, J.J., R.L. Matzkin, and L. Nesheim. 2010b. Supplement to "Nonparametric Estimation of Nonadditive Hedonic Models": Technical Appendix. https://www.econometricsociety.org/ecta/supmat/6388_extensions.pdf.

Keane, M.P., and K.I. Wolpin. 1997. The Career Decisions of Young Men. Journal of Political Economy 105(3): 473-522.

Kennan, J., and J.R. Walker. 2011. The Effect of Expected Income on Individual Migration Decisions. Econometrica 79(1): 211-51.

Kuminoff, N.V. 2012. "Recovering Preferences from a Dual-Market Locational Equilibrium, mimeo.

Kuminoff, N.V., and J.C. Pope. 2012. A Novel Approach to Identifying Hedonic Demand Parameters. Economics Letters 116(3):374-6. 
Kuminoff, N.V., and J.C. Pope. 2014. Do "Capitalization Effects" for Public Goods Reveal the Public's Willingness to Pay? International Economic Review 55(4): 1227-50.

Kuminoff, N.V., V.K. Smith, and C. Timmins. 2013. The New Economics of Equilibrium Sorting and Policy Evaluation Using Housing Markets. Journal of Economic Literature 51(4): 100762.

Lind, R.C. 1973. Spatial Equilibrium, the Theory of Rents, and the Measurement of Benefits from Public Programs. Quarterly Journal of Economics 87(2): 188-207.

Milgrom, P., and C. Shannon. 1994. Monotone Comparative Statics. Econometrica 62: 157-80.

Palmquist, R.B. 1984. Estimating the Demand for Characteristics of Housing. Review of Economics and Statistics 66(3): 394-404.

Palmquist, R.B. 2005. Property Value Models. In Handbook of Environmental Economics, ed. by K.G. Mäler and J.R. Vincent. Amsterdam: North-Holland.

Pollak, Robert A. 1989. The Theory of the Cost-of-Living Index. New York: Oxford University Press.

Rosen, S. 1974. Prices and Implicit Markets: Product Differentiation in Pure Competition. Journal of Political Economy 82(1): 34-55.

Scotchmer, S. 1986. The Short-Run and Long-Run Benefits of Environmental Improvement. Journal of Public Economics 30(1): 61-81.

Sieg, H., V.K. Smith, H.S. Banzhaf, and R. Walsh. 2004. Estimating the General Equilibrium Benefits of Large Changes in Spatially Delineated Public Goods. International Economic Review 45(4): 1047-77.

Stapleford, T.A. 2011. Aftershocks from a Revolution: Ordinal Utility and Cost-of-Living Indexes. Journal of the History of Economic Thought 33(2): 187-222.

Starrett, D.A. 1981. Land Value Capitalization in Local Public Finance. Journal of Political Economy 89(2): 306-327.

Timmins, C. 2006. Estimating Spatial Differences in the Brazilian Cost of Living with Household Location Choices. Journal of Development Economics 80(1): 59-83.

Von Haefen, R.H. 2007. Empirical Strategies for Incorporating Weak Complementarity into Consumer Demand Models." Journal of Environmental Economics and Management 54(1): 1531.

Wilson, R.B. 1993. Nonlinear Pricing. New York: Oxford. 
Figure 1. Willingness to pay for non-marginal changes in public goods

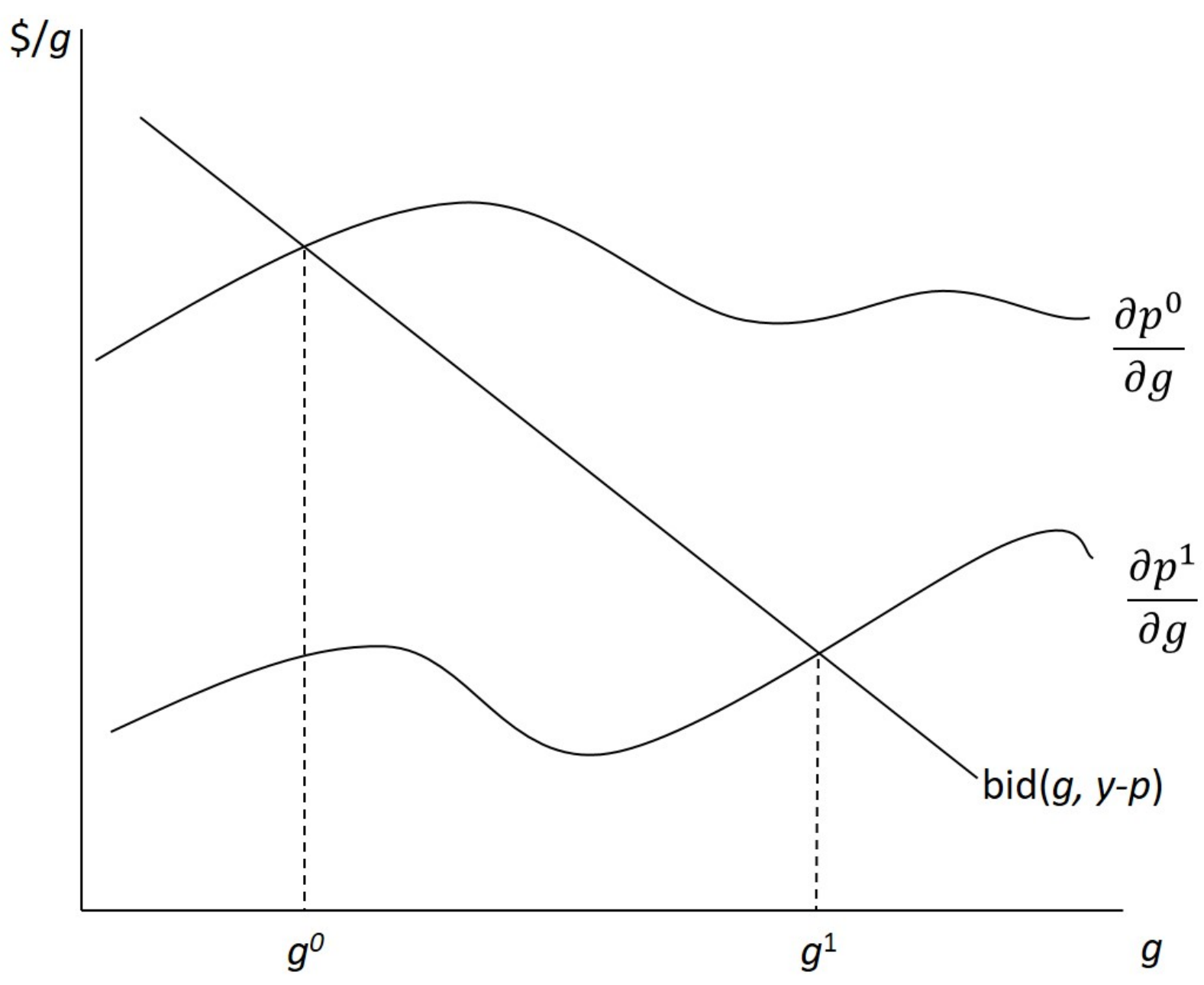


Figure 2. Household sorting is unobserved

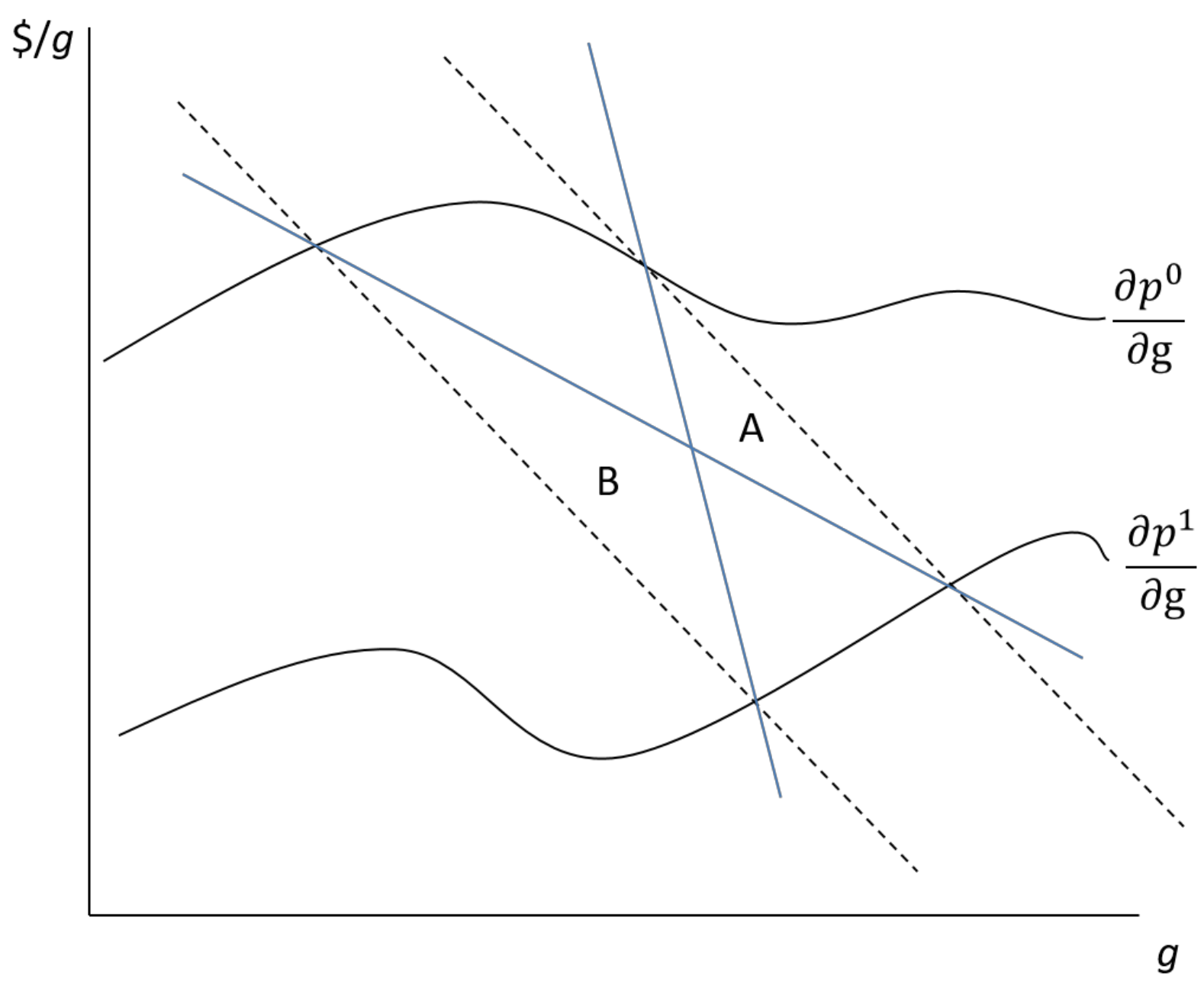


Figure 3. Depiction of Simulated Hedonic Equilibrium for One Representative Policy

A. CDFs of $g$

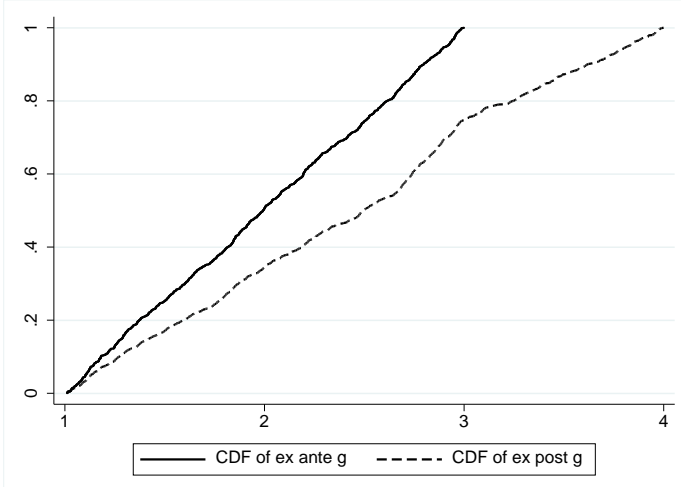

B. Hedonic Price Functions

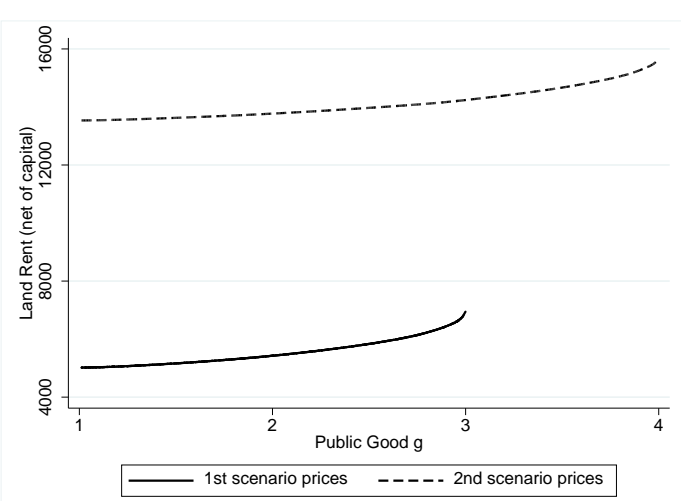

C. Marginal Prices

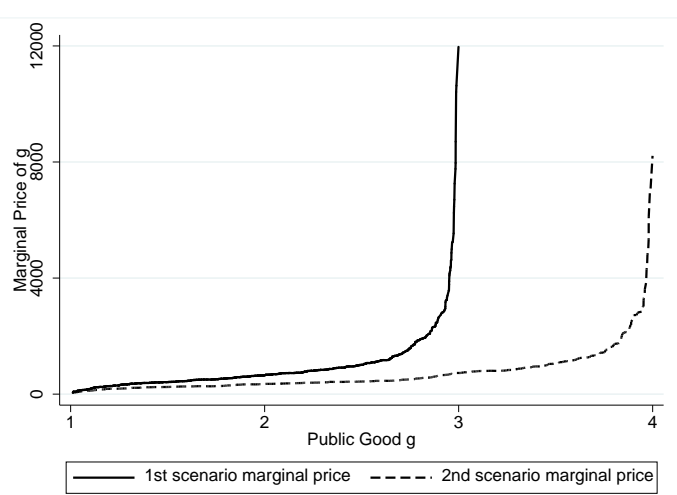


Figure 4. Depiction of Results for One Representative Simulation: Estimated Hedonic Derivative and Marginal WTP, Epple-Sieg Utility Function

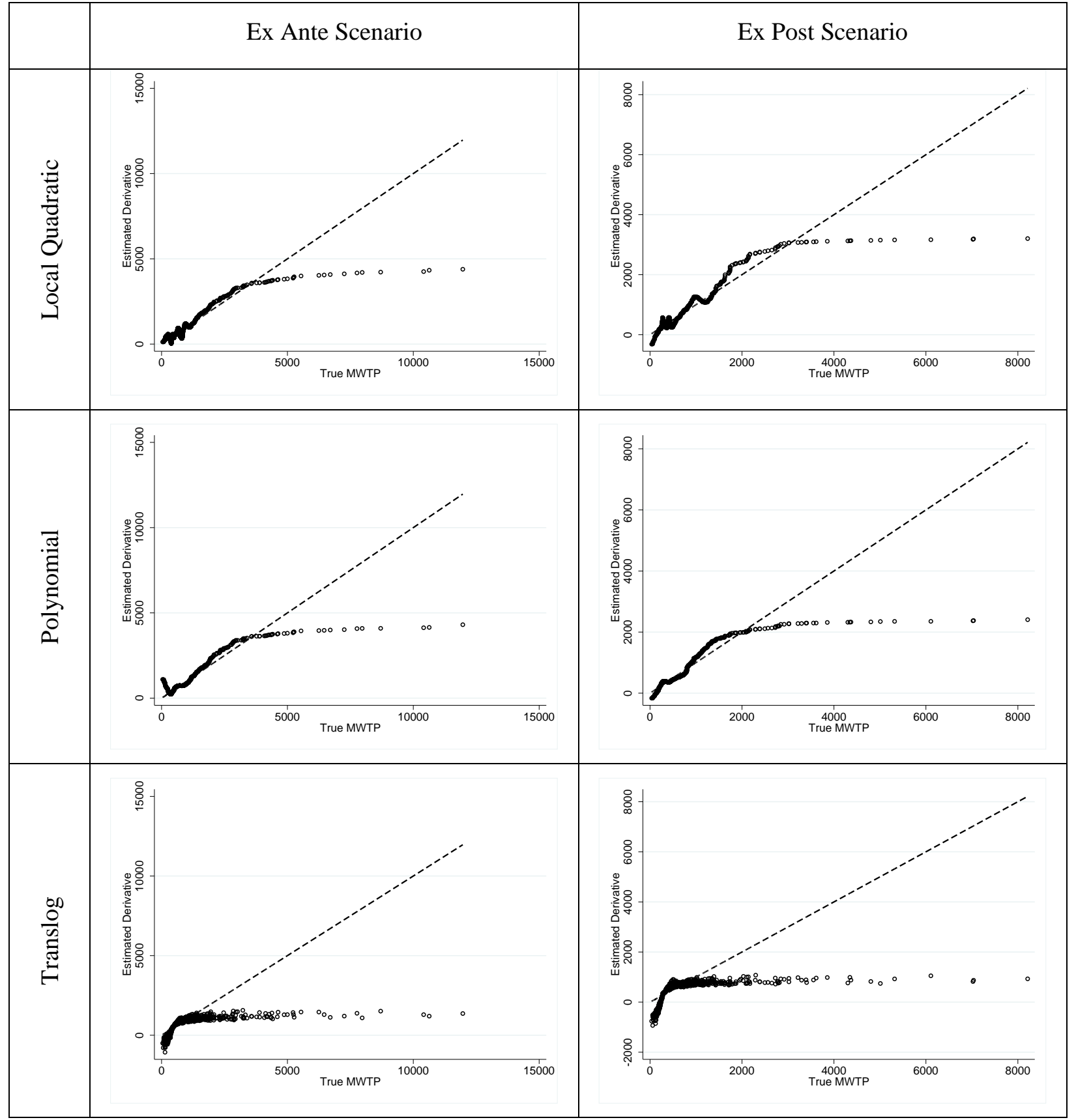


Figure 5. Sorting Behavior (One Representative Simulation using Epple-Sieg Utility Function)

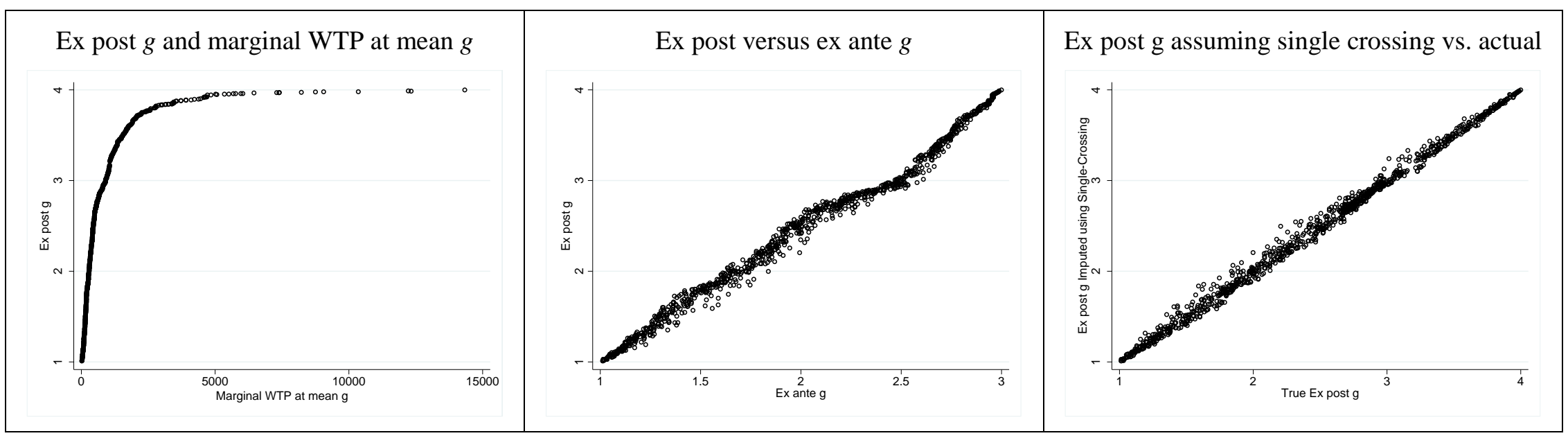


Table 1. Results of Simulations: No Transactions Costs

\begin{tabular}{|c|c|c|c|c|c|c|c|c|}
\hline \multirow{3}{*}{$\begin{array}{l}\text { Statistic } \\
\text { (Averaged over } \\
\text { households) }\end{array}$} & \multicolumn{8}{|c|}{$\begin{array}{l}\text { Mean Value Across } 100 \text { Simulations } \\
\text { (5 } 5^{\text {th }} \text { and } 95^{\text {th }} \text { Percentiles in Parentheses) }\end{array}$} \\
\hline & \multicolumn{4}{|c|}{ Epple-Sieg Model } & \multicolumn{4}{|c|}{ Repackaging Model } \\
\hline & $\begin{array}{l}\text { True Mar- } \\
\text { ginal Values }\end{array}$ & $\begin{array}{c}\text { Semi- } \\
\text { Parametric }\end{array}$ & Polynomial & Translog & $\begin{array}{c}\text { True Mar- } \\
\text { ginal Values }\end{array}$ & $\begin{array}{c}\text { Semi- } \\
\text { Parametric }\end{array}$ & Polynomial & Translog \\
\hline Average CV & \multirow{2}{*}{\multicolumn{4}{|c|}{$\begin{array}{c}\$ 506 \\
(448-562) \\
\$ 430 \\
(371-485)\end{array}$}} & \multirow{2}{*}{\multicolumn{4}{|c|}{$\begin{array}{c}\$ 532 \\
(494-564) \\
\$ 523 \\
(487-556)\end{array}$}} \\
\hline Average EV & & & & & & & & \\
\hline $\begin{array}{l}\text { Value of Eq. (9), } \\
\text { as avg. }\end{array}$ & $\begin{array}{c}\$ 477 \\
(428-530)\end{array}$ & $\begin{array}{c}\$ 437 \\
(386-489)\end{array}$ & $\begin{array}{c}\$ 432 \\
(378-483)\end{array}$ & $\begin{array}{c}\$ 749 \\
(634-836)\end{array}$ & $\begin{array}{c}\$ 532 \\
(494-564)\end{array}$ & $\begin{array}{c}\$ 520 \\
(484-562)\end{array}$ & $\begin{array}{c}\$ 521 \\
(483-563)\end{array}$ & $\begin{array}{c}\$ 918 \\
(847-984)\end{array}$ \\
\hline \multicolumn{9}{|c|}{ When Households Are Not Observed } \\
\hline Lower Bound & $\begin{array}{c}\$ 107 \\
(53-150)\end{array}$ & $\begin{array}{c}\$ 110 \\
(25-171)\end{array}$ & $\begin{array}{c}\$ 133 \\
(64-188)\end{array}$ & $\begin{array}{c}\$ 515 \\
(390-619)\end{array}$ & $\begin{array}{c}\$ 430 \\
(397-466)\end{array}$ & $\begin{array}{c}\$ 422 \\
(361-480)\end{array}$ & $\begin{array}{c}\$ 422 \\
(370-476)\end{array}$ & $\begin{array}{c}\$ 834 \\
(758-891)\end{array}$ \\
\hline Upper Bound & $\begin{array}{c}\$ 524 \\
(463-593)\end{array}$ & $\begin{array}{c}\$ 503 \\
(425-580)\end{array}$ & $\begin{array}{c}\$ 471 \\
(407-553)\end{array}$ & $\begin{array}{c}\$ 812 \\
(688-905)\end{array}$ & $\begin{array}{c}\$ 576 \\
(537-611)\end{array}$ & $\begin{array}{c}\$ 583 \\
(534-643)\end{array}$ & $\begin{array}{c}\$ 575 \\
(530-639)\end{array}$ & $\begin{array}{c}\$ 987 \\
(909-1058)\end{array}$ \\
\hline $\begin{array}{l}\text { Imposing Single } \\
\text { Crossing }\end{array}$ & $\begin{array}{c}\$ 477 \\
(429-530)\end{array}$ & $\begin{array}{c}\$ 437 \\
(386-491)\end{array}$ & $\begin{array}{c}\$ 433 \\
(379-483)\end{array}$ & $\begin{array}{c}\$ 748 \\
(628-836)\end{array}$ & $\begin{array}{c}\$ 532 \\
(494-564)\end{array}$ & $\begin{array}{c}\$ 519 \\
(478-558)\end{array}$ & $\begin{array}{c}\$ 521 \\
(483-563)\end{array}$ & $\begin{array}{c}\$ 917 \\
(846-984)\end{array}$ \\
\hline
\end{tabular}


Table 2a. Results of Simulations: Transactions Costs of $\mathbf{\$ 4 0 0 0}$

\begin{tabular}{|c|c|c|c|c|c|c|c|c|}
\hline \multirow{3}{*}{$\begin{array}{l}\text { Statistic } \\
\text { (Averaged over } \\
\text { households) }\end{array}$} & \multicolumn{8}{|c|}{$\begin{array}{l}\text { Mean Value Across } 100 \text { Simulations } \\
\left(5^{\text {th }} \text { and } 95^{\text {th }} \text { Percentiles in Parentheses) }\right.\end{array}$} \\
\hline & \multicolumn{4}{|c|}{ Epple-Sieg Model } & \multicolumn{4}{|c|}{ Repackaging Model } \\
\hline & $\begin{array}{l}\text { True Mar- } \\
\text { ginal Values }\end{array}$ & $\begin{array}{l}\text { Semi- } \\
\text { Parametric }\end{array}$ & Polynomial & Translog & $\begin{array}{l}\text { True Mar- } \\
\text { ginal Values }\end{array}$ & $\begin{array}{l}\text { Semi- } \\
\text { Parametric }\end{array}$ & Polynomial & Translog \\
\hline Average CV & \multirow{2}{*}{\multicolumn{4}{|c|}{$\begin{array}{c}\$ 389 \\
(329-448) \\
\$ 368 \\
(313-421)\end{array}$}} & \multirow{2}{*}{\multicolumn{4}{|c|}{$\begin{array}{c}\$ 444 \\
(408-473) \\
\$ 443 \\
(411-473)\end{array}$}} \\
\hline Average EV & & & & & & & & \\
\hline $\begin{array}{l}\text { Value of Eq. (9), } \\
\text { as avg. }\end{array}$ & $\begin{array}{c}\$ 351 \\
(307-400)\end{array}$ & $\begin{array}{c}\$ 403 \\
(342-462)\end{array}$ & $\begin{array}{c}\$ 387 \\
(331-442)\end{array}$ & $\begin{array}{c}\$ 401 \\
(335-468)\end{array}$ & $\begin{array}{c}\$ 449 \\
(412-480)\end{array}$ & $\begin{array}{c}\$ 542 \\
(499-592)\end{array}$ & $\begin{array}{c}\$ 543 \\
(492-594)\end{array}$ & $\begin{array}{c}\$ 755 \\
(703-800)\end{array}$ \\
\hline $\begin{array}{l}\text { Lower Bound } \\
\text { from } \S 5\end{array}$ & $\begin{array}{c}\$ 215 \\
(171-258)\end{array}$ & $\begin{array}{c}\$ 197 \\
(149-240)\end{array}$ & $\begin{array}{c}\$ 195 \\
(148-236)\end{array}$ & $\begin{array}{c}\$ 273 \\
(199-355)\end{array}$ & $\begin{array}{c}\$ 55 \\
(40-75)\end{array}$ & $\begin{array}{c}\$ 52 \\
(36-71)\end{array}$ & $\begin{array}{c}\$ 52 \\
(37-71)\end{array}$ & $\begin{array}{c}\$ 341 \\
(304-383)\end{array}$ \\
\hline $\begin{array}{l}\text { Upper Bound } \\
\text { from } \S 5\end{array}$ & $\begin{array}{c}\$ 391 \\
(343-442)\end{array}$ & $\begin{array}{c}\$ 453 \\
(384-521)\end{array}$ & $\begin{array}{c}\$ 422 \\
(365-482)\end{array}$ & $\begin{array}{c}\$ 328 \\
(277-381)\end{array}$ & $\begin{array}{c}\$ 499 \\
(459-534)\end{array}$ & $\begin{array}{c}\$ 491 \\
(448-541)\end{array}$ & $\begin{array}{c}\$ 607 \\
(552-664)\end{array}$ & $\begin{array}{c}\$ 469 \\
(395-534)\end{array}$ \\
\hline \multicolumn{9}{|c|}{ When Households Are Not Observed } \\
\hline Upper Bound & $\begin{array}{c}\$ 467 \\
(411-534)\end{array}$ & $\begin{array}{c}\$ 529 \\
(444-631)\end{array}$ & $\begin{array}{c}\$ 486 \\
(417-564)\end{array}$ & $\begin{array}{c}\$ 483 \\
(408-564)\end{array}$ & $\begin{array}{c}\$ 492 \\
(457-524)\end{array}$ & $\begin{array}{c}\$ 635 \\
(571-701)\end{array}$ & $\begin{array}{c}\$ 623 \\
(547-688)\end{array}$ & $\begin{array}{c}\$ 811 \\
(752-866)\end{array}$ \\
\hline $\begin{array}{l}\text { Upper Bound } \\
\text { (Constrained) }\end{array}$ & $\begin{array}{c}\$ 454 \\
(401-517)\end{array}$ & $\begin{array}{c}\$ 515 \\
(432-607)\end{array}$ & $\begin{array}{c}\$ 472 \\
(410-542)\end{array}$ & $\begin{array}{c}\$ 475 \\
(401-555)\end{array}$ & $\begin{array}{c}\$ 463 \\
(429-495)\end{array}$ & $\begin{array}{c}\$ 566 \\
(521-615)\end{array}$ & $\begin{array}{c}\$ 564 \\
(511-623)\end{array}$ & $\begin{array}{c}\$ 803 \\
(747-858)\end{array}$ \\
\hline
\end{tabular}


Table 2b. Results of Simulations: Transactions Costs of $\mathbf{\$ 8 0 0 0}$

\begin{tabular}{|c|c|c|c|c|c|c|c|c|}
\hline \multirow{3}{*}{$\begin{array}{l}\text { Statistic } \\
\text { (Averaged over } \\
\text { households) }\end{array}$} & \multicolumn{8}{|c|}{$\begin{array}{l}\text { Mean Value Across } 100 \text { Simulations } \\
\text { (5 } 5^{\text {th }} \text { and } 95^{\text {th }} \text { Percentiles in Parentheses) }\end{array}$} \\
\hline & \multicolumn{4}{|c|}{ Epple-Sieg Model } & \multicolumn{4}{|c|}{ Repackaging Model } \\
\hline & $\begin{array}{l}\text { True Mar- } \\
\text { ginal Values }\end{array}$ & $\begin{array}{l}\text { Semi- } \\
\text { Parametric }\end{array}$ & Polynomial & Translog & $\begin{array}{l}\text { True Mar- } \\
\text { ginal Values }\end{array}$ & $\begin{array}{l}\text { Semi- } \\
\text { Parametric }\end{array}$ & Polynomial & Translog \\
\hline Average CV & \multirow{2}{*}{\multicolumn{4}{|c|}{$\begin{array}{c}\$ 355 \\
(298-408) \\
\$ 318 \\
(268-370)\end{array}$}} & \multirow{2}{*}{\multicolumn{4}{|c|}{$\begin{array}{c}\$ 440 \\
(404-471) \\
\$ 429 \\
(394-460)\end{array}$}} \\
\hline Average EV & & & & & & & & \\
\hline $\begin{array}{l}\text { Value of Eq. (9), } \\
\text { as avg. }\end{array}$ & $\begin{array}{c}\$ 318 \\
(277-363)\end{array}$ & $\begin{array}{c}\$ 449 \\
(385-517)\end{array}$ & $\begin{array}{c}\$ 431 \\
(366-492)\end{array}$ & $\begin{array}{c}\$ 330 \\
(288-382)\end{array}$ & $\begin{array}{c}\$ 444 \\
(407-476)\end{array}$ & $\begin{array}{c}\$ 578 \\
(525-631)\end{array}$ & $\begin{array}{c}\$ 573 \\
(520-627)\end{array}$ & $\begin{array}{c}\$ 733 \\
(681-777)\end{array}$ \\
\hline $\begin{array}{l}\text { Lower Bound } \\
\text { from } \S 5\end{array}$ & $\begin{array}{c}\$ 100 \\
(71-138)\end{array}$ & $\begin{array}{c}\$ 82 \\
(50-113)\end{array}$ & $\begin{array}{c}\$ 78 \\
(49-106)\end{array}$ & $\begin{array}{c}\$ 91 \\
(59-124)\end{array}$ & $\begin{array}{c}\$ 7 \\
(2-15)\end{array}$ & $\begin{array}{c}\$ 6 \\
(1-14)\end{array}$ & $\begin{array}{c}\$ 6 \\
(2-14)\end{array}$ & $\begin{array}{c}\$ 265 \\
(239-288)\end{array}$ \\
\hline $\begin{array}{l}\text { Upper Bound } \\
\text { from } \S 5\end{array}$ & $\begin{array}{c}\$ 382 \\
(335-434)\end{array}$ & $\begin{array}{c}\$ 569 \\
(491-653)\end{array}$ & $\begin{array}{c}\$ 520 \\
(440-586)\end{array}$ & $\begin{array}{c}\$ 315 \\
(270-353)\end{array}$ & $\begin{array}{c}\$ 497 \\
(456-532)\end{array}$ & $\begin{array}{c}\$ 491 \\
(449-540)\end{array}$ & $\begin{array}{c}\$ 682 \\
(608-753)\end{array}$ & $\begin{array}{c}\$ 447 \\
(395-499)\end{array}$ \\
\hline \multicolumn{9}{|c|}{ When Households Are Not Observed } \\
\hline Upper Bound & $\begin{array}{c}\$ 404 \\
(348-471)\end{array}$ & $\begin{array}{c}\$ 603 \\
(490-728)\end{array}$ & $\begin{array}{c}\$ 535 \\
(436-626)\end{array}$ & $\begin{array}{c}\$ 384 \\
(337-438)\end{array}$ & $\begin{array}{c}\$ 458 \\
(422-491)\end{array}$ & $\begin{array}{c}\$ 695 \\
(604-801)\end{array}$ & $\begin{array}{c}\$ 662 \\
(583-748)\end{array}$ & $\begin{array}{c}\$ 763 \\
(700-822)\end{array}$ \\
\hline $\begin{array}{l}\text { Upper Bound } \\
\text { (Constrained) }\end{array}$ & $\begin{array}{c}\$ 390 \\
(338-452)\end{array}$ & $\begin{array}{c}\$ 587 \\
(477-711)\end{array}$ & $\begin{array}{c}\$ 520 \\
(426-609)\end{array}$ & $\begin{array}{c}\$ 378 \\
(331-431)\end{array}$ & $\begin{array}{c}\$ 448 \\
(412-479)\end{array}$ & $\begin{array}{c}\$ 601 \\
(545-661)\end{array}$ & $\begin{array}{c}\$ 588 \\
(532-649)\end{array}$ & $\begin{array}{c}\$ 753 \\
(694-809)\end{array}$ \\
\hline
\end{tabular}


Table 3. Application to Crime in San Francisco, 1999-2000.

\begin{tabular}{ll}
\hline Method & Value \\
\hline Equation (11) (single crossing) & $\$ 236.08$ \\
Lower Bound from §5 & $\$ 235.30$ \\
Upper Bound from §5 & $\$ 568.56$ \\
\hline Equation (11) (single crossing) (adjusted) & $\$ 185.15$ \\
Lower Bound from §5 (adjusted) & $\$ 182.70$ \\
\hline Upper Bound from §5 (adjusted) & $\$ 515.22$ \\
\hline Rosen two-stage (from Bishop \& Timmins [2019]) & $\$ 184.93$ \\
\hline Bishop \& Timmins (2019) MLE method & $-\$ 156.41$ \\
\hline \hline
\end{tabular}




\section{Appendix. Proofs of lemmas and Propositions.}

\section{Proof of Lemma 1.}

Since the marginal utilities are functions of $p$ and $\mathbf{z}$, we can write Equation (3) in terms of changes in marginal utilities, $\Delta\left(\frac{\partial v_{i}}{\partial p}\right)$ and $\Delta\left(\frac{\partial v_{i}}{\partial z_{j}}\right)$. With this notation, Equation (3) simplifies to:

$$
\begin{aligned}
\Delta v_{i} \approx \frac{\partial v_{i}}{\partial y}\left(\Delta y_{i}-\Delta p_{i}\right)+\sum_{j} \frac{\partial v_{i}}{\partial z_{j}} \Delta z_{j, i} & \\
+ & \frac{1}{2}\left(\Delta\left(\frac{\partial v_{i}}{\partial y}\right)\left(\Delta y_{i}-\Delta p_{i}\right)+\sum_{j} \Delta\left(\frac{\partial v_{i}}{\partial z_{j}}\right) \Delta z_{j, i}\right) .
\end{aligned}
$$

Taking the total derivative of the household's first-order condition given by (1) we have

$$
\Delta\left(\frac{\partial v_{i}}{\partial z_{j}}\right)=\left.\Delta \lambda_{i} \frac{\partial p^{0}}{\partial z_{j}}\right|_{\mathbf{z}_{i}^{0}}+\lambda_{i}^{0} \Delta\left(\frac{\partial p}{\partial z_{j}}\right)+\Delta \lambda_{i} \Delta\left(\frac{\partial p}{\partial z_{j}}\right)
$$

where $\Delta\left(\frac{\partial p}{\partial z_{j}}\right)=\left.\frac{\partial p^{1}}{\partial z_{j}}\right|_{\mathbf{z}_{i}^{1}}-\left.\frac{\partial p^{0}}{\partial z_{j}}\right|_{\mathbf{z}_{i}^{0}}$; that is, it is the change in the derivative of the price function from both the change in the price function itself and from the change in the point where it is evaluated. Inserting this expression along with $\frac{\partial v}{\partial y}=\lambda$ into (16), we have:

$$
\begin{aligned}
\Delta v_{i} \approx\left(\Delta y_{i}-\right. & \left.\Delta p_{i}\right)\left(\lambda_{i}^{0}+\frac{1}{2} \Delta \lambda_{i}\right)+\sum_{j}\left(\left.\frac{\partial p^{0}}{\partial z_{j}}\right|_{\mathrm{z}_{i}^{0}}\right) \Delta z_{j, i}\left(\lambda_{i}^{0}+\frac{1}{2} \Delta \lambda_{i}\right) \\
& +\frac{1}{2} \sum_{j} \Delta\left(\frac{\partial p}{\partial z_{j}}\right) \Delta z_{j, i} \lambda_{i}^{0}+\frac{1}{2} \sum_{j} \Delta\left(\frac{\partial p}{\partial z_{j}}\right) \Delta z_{j, i} \Delta \lambda_{i} .
\end{aligned}
$$

Writing the last term as $\frac{1}{4} \sum_{j} \Delta\left(\frac{\partial p}{\partial z_{j}}\right) \Delta z_{j, i} \Delta \lambda_{i}+\frac{1}{4} \sum_{j} \Delta\left(\frac{\partial p}{\partial z_{j}}\right) \Delta z_{j, i} \Delta \lambda_{i}$, and combing the first of these two parts with the previous term, we have: 


$$
\begin{aligned}
\Delta v_{i} \approx\left(\Delta y_{i}-\right. & \left.\Delta p_{i}\right)\left(\lambda_{i}^{0}+\frac{1}{2} \Delta \lambda_{i}\right)+\sum_{j}\left(\left.\frac{\partial p^{0}}{\partial z_{j}}\right|_{\mathrm{z}_{i}^{0}}\right) \Delta z_{j, i}\left(\lambda_{i}^{0}+\frac{1}{2} \Delta \lambda_{i}\right) \\
& +\frac{1}{2} \sum_{j} \Delta\left(\frac{\partial p}{\partial z_{j}}\right) \Delta z_{j, i}\left(\lambda_{i}^{0}+\frac{1}{2} \Delta \lambda_{i}\right) \\
& +\frac{1}{4} \sum_{j} \Delta\left(\frac{\partial p}{\partial z_{j}}\right) \Delta z_{j, i} \Delta \lambda_{i} .
\end{aligned}
$$

Re-arranging, and ignoring the remaining third-order terms (as we are taking a second-order approximation), we have the desired expression. Note to compute this expression, we need Assumption $\mathrm{A} 1$, that the price derivatives and $\Delta z$ terms can be computed for each household across time.

\section{Proof of Lemma 2.}

The proof follows a similar outline as that for Lemma 1. Since the marginal costs are functions of $\mathbf{x}$, we can write Equation (5) in terms of changes in marginal costs $\Delta\left(\frac{\partial c_{h}}{\partial x_{r}}\right)$. With this notation, Equation (5) can be re-written as:

$$
\Delta c_{h} \approx \sum_{r}\left(\frac{\partial c_{h}}{\partial x_{r}}+\frac{1}{2} \Delta\left(\frac{\partial c_{h}}{\partial x_{r}}\right)\right) \Delta x_{r, h}
$$

Substituting the first-order condition (2), we now have:

$$
\begin{aligned}
\Delta c_{h} \approx \sum_{r}\left(\left.\frac{\partial p^{0}}{\partial x_{r}}\right|_{\mathbf{x}_{h}^{0}}+\frac{1}{2} \Delta\left(\frac{\partial p}{\partial x_{r}}\right)\right) \Delta x_{r, h} \\
=\sum_{r} \frac{1}{2}\left(\left.\frac{\partial p^{0}}{\partial x_{r}}\right|_{\mathbf{x}_{h}^{0}}+\left.\frac{\partial p^{1}}{\partial x_{r}}\right|_{\mathbf{x}_{h}^{1}}\right) \Delta x_{r, h}
\end{aligned}
$$

Substituting this expression into the equation $\Delta \pi=\Delta p-\Delta c$ completes the proof.

\section{Proof of Proposition 3.}

Let $\varsigma$ be the set of all feasible ways households could sort over the two time periods (i.e. all sets 
$\left\{I_{h, h^{\prime}}\right\}$ meeting the two constraints in the Proposition). Let $f\left(\left\{I_{h, h^{\prime}}\right\}\right)$ map these feasible sortings into the welfare measure given in the Proposition (in square brackets). As $\S$ is compact, there is some $\left\{I_{h, h^{\prime}}\right\}^{L},\left\{I_{h, h^{\prime}}\right\}^{U} \in$ 厄 such that $f\left(\left\{I_{h, h^{\prime}}\right\}^{L}\right) \leq f\left(\left\{I_{h, h^{\prime}}\right\}\right) \leq f\left(\left\{I_{h, h^{\prime}}\right\}^{U}\right)$, for all $\left\{I_{h, h^{\prime}}\right\}$. From Proposition 2, there is one (unknown) set $\left\{I_{h, h^{\prime}}\right\}^{*} \in \varsigma$ for which the expression in brackets gives the second order approximation to welfare. Therefore, $f\left(\left\{I_{h, h^{\prime}}\right\}^{L}\right) \leq f\left(\left\{I_{h, h^{\prime}}\right\}^{*}\right) \leq f\left(\left\{I_{h, h^{\prime}}\right\}^{U}\right)$.

\section{Proof of Proposition 5.}

Consider the initial equilibrium described by the hedonic price function $p^{0}\left(g, \mathbf{x} ; F^{0}\right)$. Now consider a change in the distribution of $g$ and allow preferences for individual households to change, but such that they are still distributed the same (Assumption A3'). Denote the new equilibrium price function by $p^{1}\left(g, \mathbf{x} ; F^{1}\right)$. Now consider a counter-factual scenario where the distribution of $g$ is still given by $F^{1}$ but all households have their original incomes and preferences. By Assumption A3', the equilibrium price function would still be $p^{1}\left(g, \mathbf{x} ; F^{1}\right)$ since the distribution of demands would be no different in this counterfactual and $g$ and $\mathbf{x}$ are unchanged (though the assignment of households to houses may change). But by Assumption A5 and the argument in Proposition 4 , any household choosing $z_{j}$ in the initial equilibrium such that $F_{j}^{0}\left(z_{j}\right)=\theta$ will choose $z_{j}$ in the counterfactual equilibrium such that $F_{j}^{1}\left(z_{j}\right)=\theta$. Moreover, these choices are consistent with the price equilibrium. The rest of the argument follows from Proposition 4.

Finally, note that the same argument could be made, mutatis mutandis, starting with $p^{1}($ ) and going back to $p^{0}(\mathrm{)}$ under ex post preferences. Thus, the aggregate welfare evaluation is invariant to the perspective taken.

The proof of the extension of Proposition 3 is similar. However, we now no longer need a constant joint distribution of $\left\{v^{t}, y^{t}\right\}$; instead, we only need the same distribution of $v^{1}$ conditional on $y^{1}$ as we would have had if $v$ was unchanged. 